\title{
Damage Identification Analyses of a Historic Masonry Structure in T-F Domain
}

\author{
Kemal BEYEN ${ }^{1}$
}

\begin{abstract}
Fatih mosque, a landmark structure in Istanbul, has suffered structural damage during 1999 Kocaeli earthquake. Using spectral, time-domain (OKID/ERA for SISO and MIMO models) and T-F domain (WT, HHT) techniques on ambient vibrations, damage identification has been performed. Results of parametric and spectral analyses indicate close global peaks. Northwest arch $\left(\mathrm{O}_{3}\right)$ that was expected to move in harmony with other arches cannot display such a consistent behavior and produces additional local frequency at $24 \mathrm{~Hz}$ due to damage. Southeast arch $\left(O_{1}\right)$ also has comparable damage producing another locality at $38 \mathrm{~Hz}$. Extending linear approaches into nonlinear-nonstationary methods, decompositions in WT and HHT improved the results in the temporal-frequency energy distribution. Estimated individual and global structural behavior are consistent with visually inspected damage states for $O_{3}$ and $O_{1}$. On a global scale, damage additionally generates significant nonstationarity on the neighbors in touch. Northeast arch $\left(\mathrm{O}_{2}\right)$ is affected strongly by the anomalies appeared at stations $O_{3}$ and $O_{1}$. Especially neighbor stations $O_{6}$ and $O_{7}$ located at the springing points of the arch $\left(\mathrm{O}_{3}\right)$ and others $\mathrm{O}_{5}$ and $\mathrm{O}_{6}$ located at the springing points of the arch $\left(\mathrm{O}_{2}\right)$ are strongly affected due to tension rod failure causing the dome base to open outwards. T-F analysis detects and localizes any anomalous system behavior and can adequately capture the system dynamics of any instrumented part of the structure at any particular time epoch. For historical masonry structures with vulnerable components like large central dome and arches that have low redundancy, there is a need to develop automatic signal/image processing through, machine vision, and pattern recognition for early diagnosis and warning of gradual deteriorations.
\end{abstract}

Keywords: Damage identification, nonstationary, nonlinear, wavelet analysis, HHT, T-F analysis, stone masonry structure.

\footnotetext{
Note:

- This paper has been received on May 24, 2018 and accepted for publication by the Editorial Board on October 22, 2019.

- Discussions on this paper will be accepted by May 31, 2021.

- https://dx.doi.org/10.18400/tekderg.426728

1 Kocaeli University, Department of Civil Engineering, Kocaeli, Turkey - kbeyen@kocaeli.edu.tr https://orcid.org/0000-0001-8878-0985
} 


\section{INTRODUCTION}

Turkey has a long history of destructive earthquakes. The 17 August $1999 \mathrm{M}_{\mathrm{w}}$ 7.4 Kocaeli earthquake was one of the largest earthquakes of the North Anatolian fault zone over the last five centuries. It caused widespread damage in the densely populated epicentral region. Structural damages were observed as far away as the western suburbs of Istanbul, about 110 $\mathrm{km}$ from the epicenter. Stone- masonry cultural structures were subjected to strong shaking during the Kocaeli earthquake and they are in areas of high seismic hazard from future events.

Arches and domes are vulnerable important components of stone masonry cultural structures. Damage characteristics and unique failure mechanisms of such structural systems are key issues to be identified before effective seismic risk mitigation schemes can be developed. Post-earthquake failures in aging stone masonry structures that may develop over time are also possible. Such damage patterns will become apparent as excessive cracks and inevitably, element-level spallings are initiated by seismic activities. Fatih mosque, which was originally built more than 500 years ago, suffered various kinds of damage due to large-scale earthquakes during its lifetime. During the great earthquake of 1766, many domes and arches of monumental buildings in the city, including Fatih mosque, collapsed (it was subsequently reconstructed). In the 1999 Kocaeli earthquake, the structure suffered various kinds of damage and parts of its facades fell off in many locations. Progressive damage and partial failure may destabilize the adjacent members and eventually develop a post-earthquake structural collapse. Collapse of the east arch of Hagia Sophia three years after a major earthquake in 1344 [1] is a remarkable example of a post-earthquake structural failure. To prevent such possible failures initiating collapse, real-time damage detection in a scheduled task is essential. This task can be realized within the frames of nondestructive vibration-based damage identification in a health-monitoring program.

Despite the structural simplicity and morphological clarity of the stone made dome-arch type structures, understanding and describing mechanical behavior especially under seismic loading condition is still challenging problem due to complex and nonlinear behavior of masonry structures [2]. As it is summarized by Lourenço [3], experimental and numerical issues in modelling of the mechanical behavior of masonry construction are still developing with the computational technologies. Lourenço also proposes possible guidelines with illustrations from different numerical analysis tools for historical constructions [3]. Kennedy proposed experimental modal analysis that is the first and perhaps the most significant one in 1947 [4]. Vibration based damage assessment for bridge structures was seen in the early 1980's [5]. Field tests of civil engineering structures that were studied comprehensively dates back to the early nineties $[6,7]$. Today, influence of existing cracks on the dynamic behavior of buildings, constitutive models for masonry [8,9] and level of changes in dynamic properties realistically describing the masonry building damages are some topics under consideration [10]. Moreover today, long-term structural monitoring and FEM-based damage assessment through linear [11, 12, 13] and nonlinear analysis [14] represent complementary techniques to identify the complex behavior of ancient buildings. Importance of the structural monitoring has been well understood in recent decades by the community as an identification tool for model upgrading $[15,16,17,18,19]$, a diagnosis tool for tracing progressive damage and condition assessment $[11,12,13,14]$ and control tool after the restoration or strengthening [20, 21, 22]. 
In general, ambient vibration data provides knowledge about the characteristic behavior of a structure that has two broad applications; (1) Updating member properties in an analytical model of the structure provides a rational basis for validation [16, 23]. (2) Identification of deterioration and probable failure mechanism. However, ambient vibration data recorded from historical structures contains low amplitude structural vibration signal and large amplitude wide-band noise. Therefore, in case of damage identification currently used classical methods are usually not suitable. Furthermore, analysis of deterioration requires multi-epoch ambient vibration measurements in a properly designed and continuously operated structural health-monitoring network. For the Fatih mosque, measurement program was performed in 2005, after the Kocaeli earthquake to assess the existing condition of the historical large-scale building in the class of the Imperial Ottoman mosques. The vibrations of the dome + arch type structural system are valuable post-earthquake records for the stone made structures. Recorded data sets were used first in the identification of the structural characteristics for the report, which was prepared for the restoration work undertaken by Istanbul Metropolitan Municipality [24, 25]. Later, although all were linear approaches and consistency was limited for damage identification, advanced algorithms were implemented and responses to the August 17, 1999 Kocaeli earthquake were simulated based on code proposed spectrum [26]. In this study, the aim is to identify and correlate the damage with strong evidences using nonlinear and nonstationary techniques for accurate estimation. Since as a priority, structural characteristics and as well as damage information are not known before recording, it is inevitable that the various methods are always tested with the data sets to see the level of sensitivity. Consistency between the Time-Frequency results is also investigated to assess the accuracy for each applied technique. Early results [26] were also described in part of this study. Such linear-stationary outcomes is particularly important at this time, when concerns about the nonlinear and nonstationary features of the dynamic behavior exist.

In modern construction, for instance for moment resisting-shear frame systems, damage is mostly a local phenomenon that is captured by utilizing high frequency modes, whereas the low frequency modes are related to the global response of the structure. In case of vibrationbased damage detection, studies have shown that the resonant frequencies have less random measurement errors (i.e., less effect of sampling variation) than other modal parameters, which may have many sources of error [27]. Therefore, the resonant frequency can be a robust damage indicator for historical structures with small structural redundancy. As shown in Fig. 1, the building is approximately square in plan with vertical load carrying members at the corners. Failure of any one of these members may initiate the collapse mechanism, due to poor redundancy. Damage, or lack thereof, can be evaluated comparing vibration characteristics between damaged and undamaged states of identical components. Due to reflective symmetry in both directions, considering for a moment a damaged member to be investigated and an undamaged identical member on the symmetry site referred to as a control member, frequency information of both identical structural members may correlate with each other, if no damage occurs; otherwise, comparison will reveal the detectable differences in peak frequencies [26]. Large changes will certainly give a strong anomaly, which needs to be examined in detail. A similar methodology might be applied in structural condition assessment for the cultural structures. Progressive damage might be better detected by an operational monitoring network. Simple seeking of natural/dominant frequency shift and peak drop in allowable limits over the time may be basic algorithm for detection. 
The objectives of the past studies $[24,26]$ are to infer the structural characteristics and identify the damage potential based on linearized approaches. Some of the core subjects in this research include (1) declaring the shortage of the linear techniques, (2) identifying nonstationary and nonlinear behavior in the structural response, (3) identifying the possible damage at the earliest possible stage from recorded input-output data and (4) implementing all of these procedures for the historical stone masonry structure. For a striking application, earthquake-induced damage in large components of the Ottoman royal mosque Fatih was considered as the working structure.

History of the working structure dates back to $15^{\text {th }}$ century. It was built in İstanbul between 1463 and 1470 along with a well-integrated group of appurtenant buildings. Much of it was destroyed during the 1766 earthquake. After altering the old structural system to the present one, it was reopened in 1772. However, little trace of this complex survives today. As a loadbearing system, central dome structure rests on four pointed-arches, which rise from springings of four heavy corner piers $[1,28,29,30]$. Four semi domes and four cupolas also support the central dome system. Cupolas are carried on four spherical triangular pendentives, which enable the force transition from the circular base of the dome to the rectangular base below and ultimately to the foundation by the piers. Buttresses on the sides provide important contribution to lateral resistance against the lateral forces of the earthquakes.

In the current study, the following provides a brief description of the content of the text that follows. Section 2 explains the behavior of the masonry structure with typical photographs of the damages developed in the Fatih mosque. Section 3 describes failure modes of the stone masonry arch-dome system in detail with typical photographs of the system failures from Fatih mosque. Section 4 briefly explains the time-frequeny domain advanced algorithms such as wavelet and Hilbert transforms, which have workable solutions to this challenging problem in vibration identification. In sub sections, background of the algorithms and efficiencies/drawbacks will be shortly discussed. Section 5 describes the instrumentation of the structure and data processing. Section 6 extensively discusses the results of the abovementioned techniques, improvements of the resolutions based on intrinsic mode functions, proposed improvement over the classic harmonic decompositions (i.e., FT) and efficiency of damage identification based on ambient vibration data sets. The Conclusion is given in section 7. This study would be beneficial example in order to apply for other monuments prone to earthquake damage. Techniques applied in this study would also bring a different perspective to civil engineers point of view other than classic approaches for conservation of historical structures.

\section{BEHAVIOR OF THE MASONRY STRUCTURE}

A conceptual framework, which is customary in testing documented performances with the observations, was used in this section to verify the expected cause and effect correlation in the structural behavior. While the behavior of the masonry structure is given in detail, typical photographs will be shared as damage examples of the Fatih mosque.

Mostly the accumulated effects of material degradation, ageing, overloading and foundation settlements damage historical unreinforced stone masonry structures. Due to additional loading because of change in functioning or boundary conditions due to supplementary losses 
or failures on neighbor members or due to seismic forces for which the structure had not been designed originally, structural members may undergo damage. Among the structural members, the most important members that are primarily vulnerable to earthquake damage are the vertical load carrying members, which are principally designed to resist gravity and wind loads with little or no consideration of the forces generated by the seismic effects. Nevertheless, under seismic forces they tend to interact with the surrounding frame and may result in different desirable failure modes. In general, behavior of the masonry structure is usually brittle with little or no ductility and both structural and non-structural parts suffer various types of damages varying from invisible cracking to crushing and eventually disintegration. William et al. [31] describes limitations in simulating the seismic behavior of masonry structures as follows: 'Steel and reinforced concrete are ductile materials that have linear elastic properties and good post-elastic strength characteristics. After yielding, these materials maintain most of their strength while undergoing substantial plastic deformations and they can be analyzed with reasonable accuracy using analytic or computational methods. In contrast, after cracks are initiated, the behavior of brittle, unreinforced materials, such as stone, brick, or adobe, is extremely difficult to predict even with today's advanced computational capabilities. In a brittle material, once yielding occurs, cracks develop and there is a complete loss of tensile strength.' Such a strength failure at any point in the structural member reduces the monolithic behavior of the structure and breaks down the load path. William et al., [31] also suggested that 'after cracks have developed, the seismic behavior of adobe building is dominated by the interactions among large cracked sections of the walls that rock out-of-plane and collide or rub against each other in-plane'. The primary cause of the most often observed damage is the low tensile strength of brick-mortar connections, as observed in Figure 2b. Both shear and flexural stresses develop because of the low tensile strength of the structure. Principally in-plane forces may cause tensile strength failure and diagonal cracking. Out-of-plane forces cause flexural stresses and cracking [32]. Further development of the in-plane cracks can result in a classic pier or arch failure as seen in Figures 2, 3 and $4[34,35]$. The failure of the corner member results from a combination of flexural and tensile stresses. Once the corner vertical member has failed, the adjacent arches meeting at the damaged pier are more likely to fail as the cases observed in Fatih mosque (see Figures 2 and 4 [34]) demonstrate. In contrast to this mechanism, other strength reductions take place specifically in the joint region of the dome base and main arches. Domes are very susceptible to local base problems and foundation problems due to insufficient tensile strength in the component materials. Damage at the base level of the main dome is the most probable source of loosened joint. Loosening affects the integrity at the joint between the stone blocks within a short time if the bond failure is not strengthened. Otherwise, an outward opening is triggered and large tension cracks on the body produce irreversible changes in the behavior of arch system. Such gradual deterioration may be externally detected after peeling the top lead coverage because inaccessible areas may not be detected by visual examination (see Figures 5, 6 and 7 [33, 34, 35]). As a result, the collapse of the dome will not be surprising. Such dome failures were reported in the literature for major historical earthquakes [1,30]. Signs and symptoms of weaknesses that are not practically detectable may require regular monitoring through image processing, machine vision, and pattern recognition. Further signs that may be seen on physical examination mostly affect the stability of the structure, since stone made masonry construction has a brittle behavior. Structural collapse might occur without warning due to (1) very low tensile 
strength, (2) fragile behavior of the blocks and joints, and (3) very massive body, which generates large inertia forces during earthquake shaking.

\section{FAILURE MODES OF THE STONE MASONRY ARCH-DOME SYSTEM}

Some failure modes for masonry structures that might not be expected may be well captured by fundamental mode vibration properties (mainly involving local but critical damage to arches), whereas others involving distributed deformations and damage should be reflected in the fundamental mode response. Stone masonry arches can collapse as a result of three possible failure mechanisms, namely a shear mechanism, a hinge mechanism and a combined shear-hinge mechanism. Plastic shear deformations in the bare arch system produce cracks that can kinematically define potential sliding blocks. Progressive cracks and sliding masonry units of arch skeleton will form the collapse mechanism. Transverse cracks appear at locations where the tensile strength capacity is exceeded. The hinge mechanism forms when the compressive strength capacity is reached, causing plastic deformations that produce the hinge. In combined shear-hinge mechanism, failure is developed by sliding between components under large compressive forces exceed strength capacity. On the other hand, two hinges are sufficient for collapse for a single span two-hinged arch system, which has first order indeterminacy. Critical damage location causing the collapse mechanism in a single span arch is not at the center of the span but at a quarter of the span. Main arches that work as single span vertical members in the arch plane should supply the continuity of the force flow down to the foundation. If load transfer to the springing points of the main arches, to the main piers, and to the foundations, respectively, is not realized on a regular basis, functional continuity is broken down. Broken load transmission consequently causes severely nonsymmetrical load distributions, which have the potential for causing the arch system to collapse. On the other hand, broken load flow in the arches leading to damage also causes the tension rod connection failure (bond beam failure), as seen in Fig. 7 [34], which breaks down the balance of forces and causes the dome base to open outwards. Tension rod failure on top of the arches affects the global modes at first since tension bars at the dome base act together as a diaphragm providing horizontal bracing system to resist lateral loads and transfer the loads to the vertical members. Main vertical structural members that support the adjacent arches from spring points at the corners offer little resistance to horizontal movement. This low-level redundancy known as component level redundancy affects the low frequency modes; consequently, the fundamental frequency of the structural system is shifted downward as is the case discussed in the first publication [26]. Measurements of fundamental mode frequencies and their shift between members (or over time) may have a limited ability to detect damage of the types described above that can lead to arch collapse. It is well known that frequency shifts have considerable limitations depending on structure types. For the structure under the study, substantial damage would be required to create significant frequency shift [26].

Any loose or cracked bond between stone masonry blocks that becomes visible at the face would be expected to weaken the bearing capacity of the member and decreases the compression force capacity (see Fig. 2 [25]). Such reductions will also decrease the shear strength capacity of the arch. In the absence of such damage, domes are relatively stable structures with high resistance to lateral deformations due to inherent advantages of their geometry. 


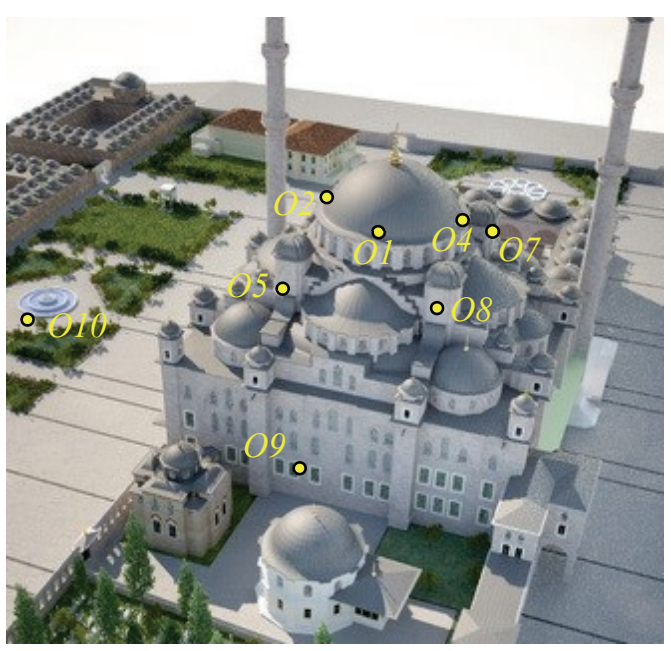

O1: On the key block of the SE arch.

O2: On the key block of the SW arch.

O3: On the key block of the NW arch.

O4: On the key block of the NE arch.

O5: On top of the South pier.

O6: On top of the West pier.

O7: On top of the North pier.

O8: On top of the East pier.

O9: At the basement.

O10: Free field observation in courtyard.

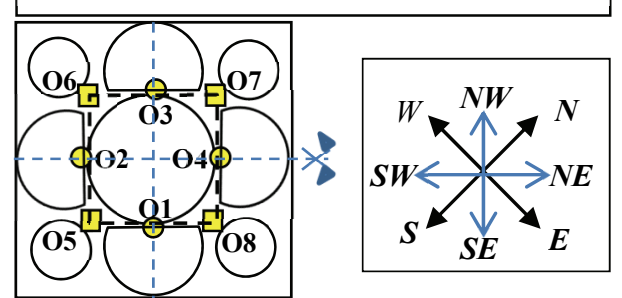

Fig. 1 - Seismometer locations from SE courtyard towards NW. Reflective symmetry in both directions in plan view is seen in the right.

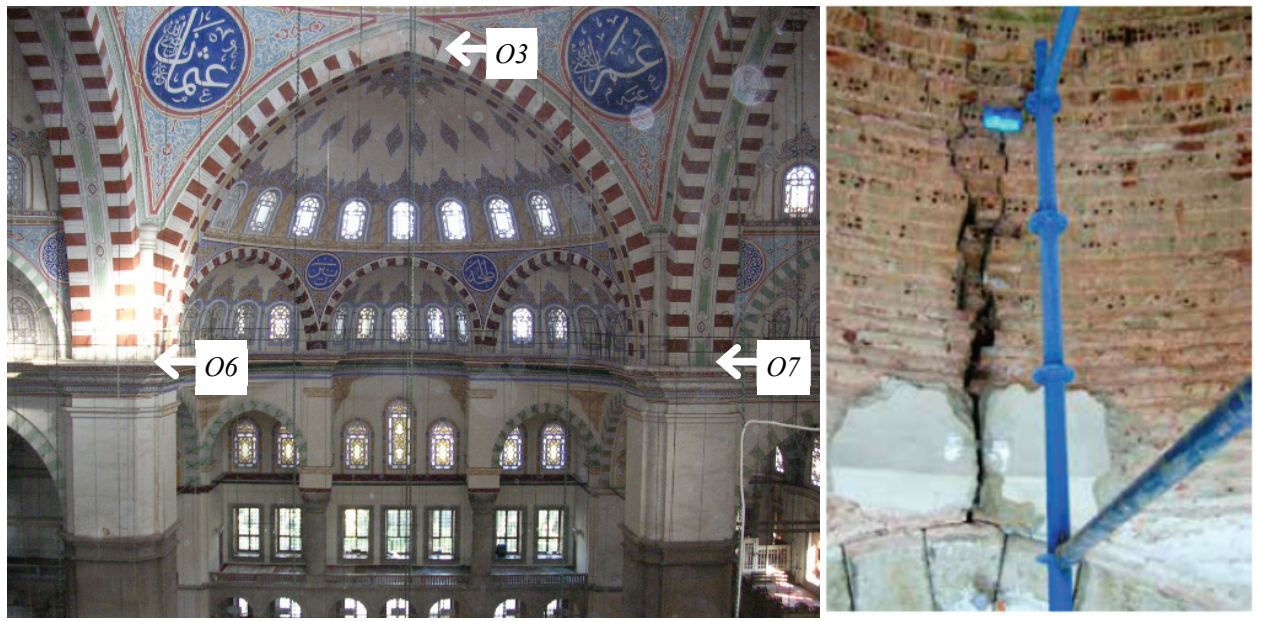

Fig. 2 - (a) From inside close look towards Northwest for station 3 at the crown of the main arch that received damage during Kocaeli earthquake of 1999; (b) Typical cracks in mortar and masonry units after scraping the top coat [25].

In case of the main arches with the interaction of dome, vaults and pillars, high lateral load resistance is possible in arch plane under static gravity and seismic loads (i.e., dynamic gravity). However, combinations of earthquake induced adverse vertical inertia forces and gravity may change the stress state from compression to tension. Such alteration may lead to stress drop, which causes damage and associated reductions in compressive capacity to 
members that typically experience only compression. Resultant tension cracks around the station 8 with lack of tension capacity and typical local openings in the window border can be seen respectively in Figures 2 and 8 [35]. In addition to this deterioration, out of plane arch deformations will further degrade the strength capacity. Such strength reductions in the arch system and at the base of the central dome cause distributed deformations and damage.

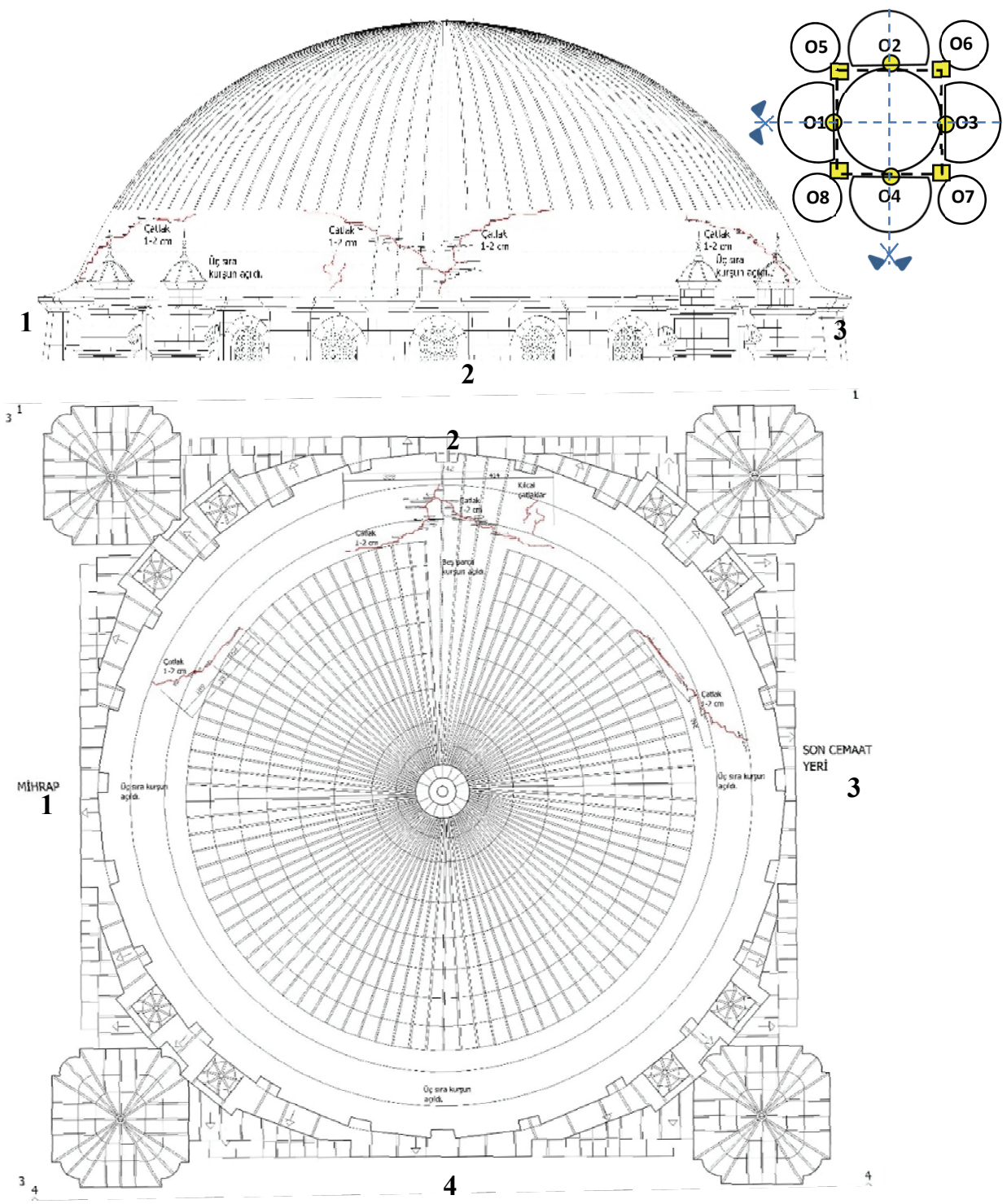

Fig. 3 - Damage patterns on the main dome in plan view (low). Damage around the stations 1, 2 and 3 from West view (top). The upper right corner (reoriented) sketch shows the instrument layout in plan view [33]. 
After removing the lead cover, tension cracks in the main dome was observed as seen in Fig. 3 [33] and large deformations on windows under the main dome base can be distinguished from Figure 4 [34, 35]. Corner dome failure next to the main pier station $7[33,34]$ also reflects the weakening of the horizontal strength between the members due to tension rod failure. The effects of such large-scale damage are observed at low frequencies [26]. In the case of the Hagia Sophia, a post-earthquake ambient vibration survey showed a drop from the pre-earthquake condition of the first two modal frequencies of approximately $4 \%-5 \%$ [36].

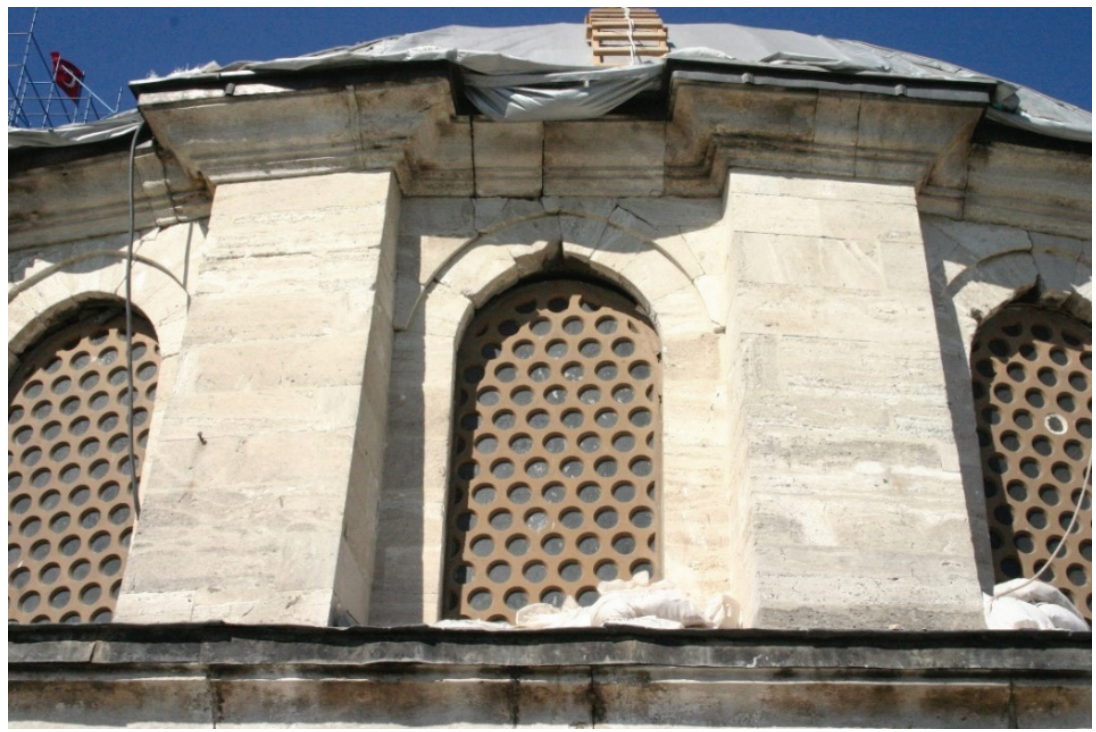

Fig - 4a Damage around station 2 [34].

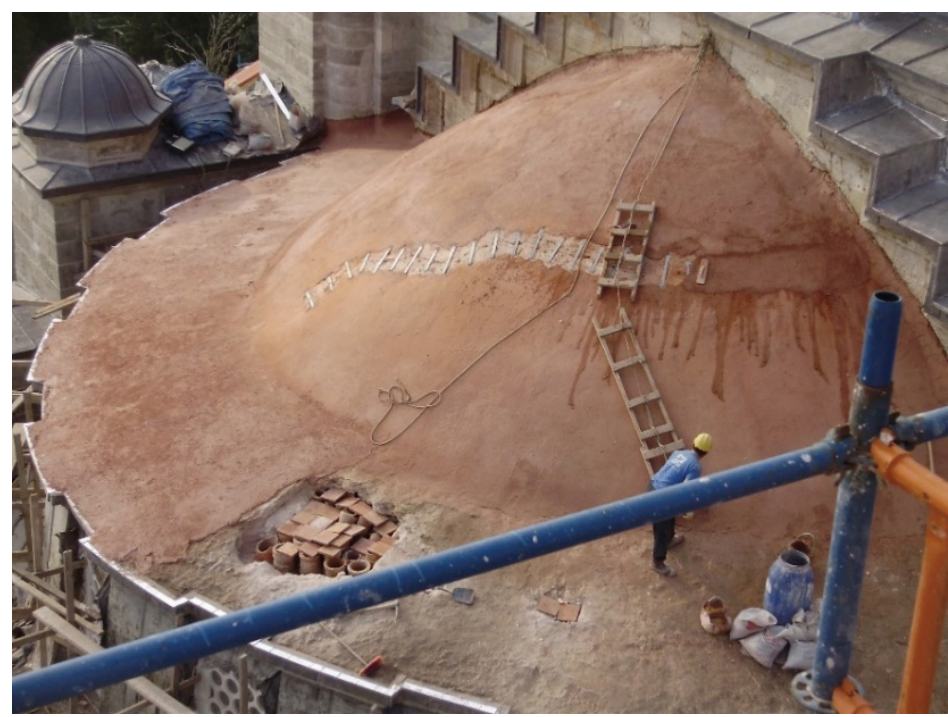

Fig. $4 b$ - Side dome view around the station 4 from outside [34] 

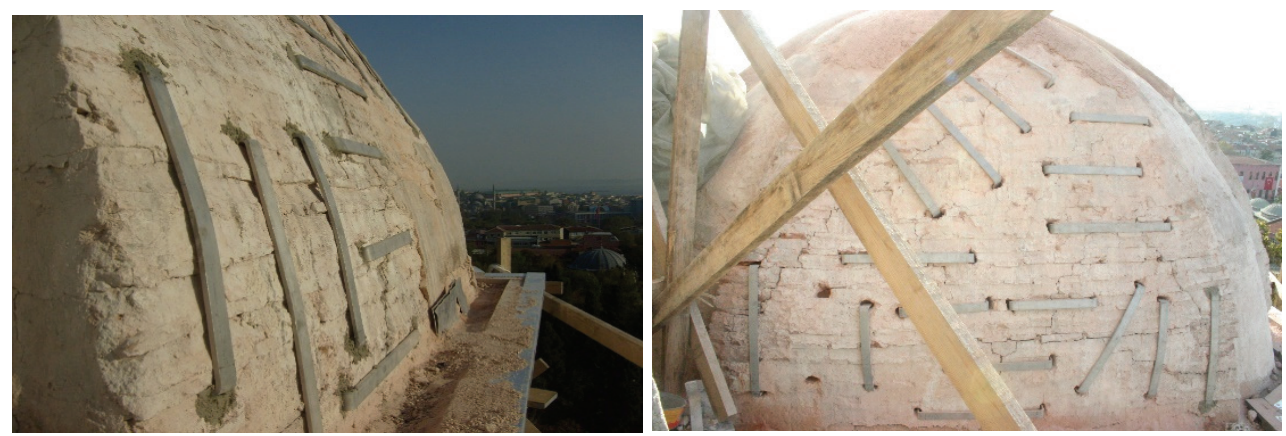

Fig. 5 - Cap view from the top of the main piers 6 and 7 [34, 35]
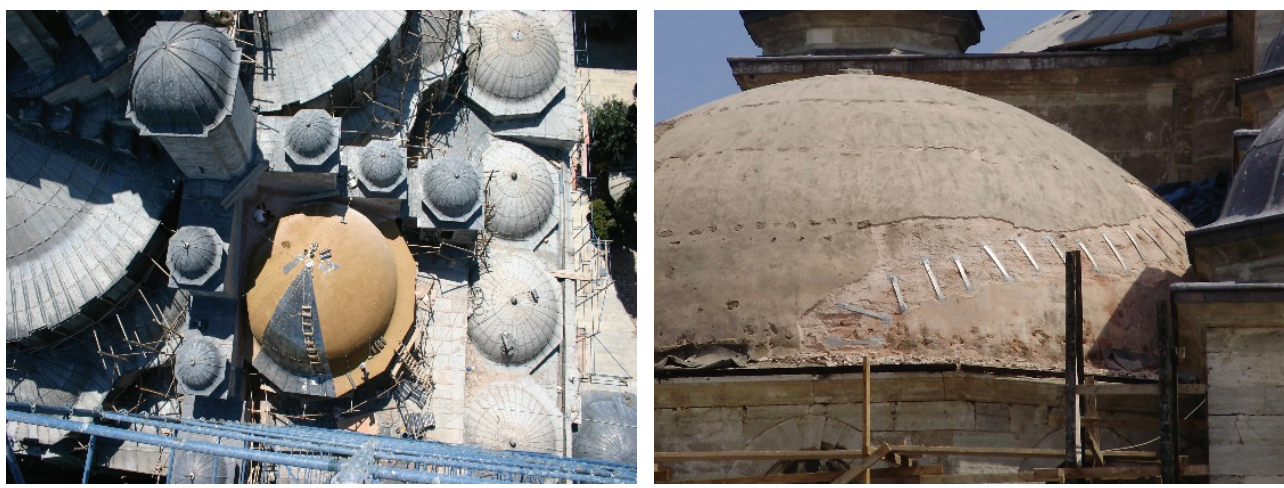

Fig. 6 - Top view from the damaged corner dome next to the main pier station 7 [33, 34]

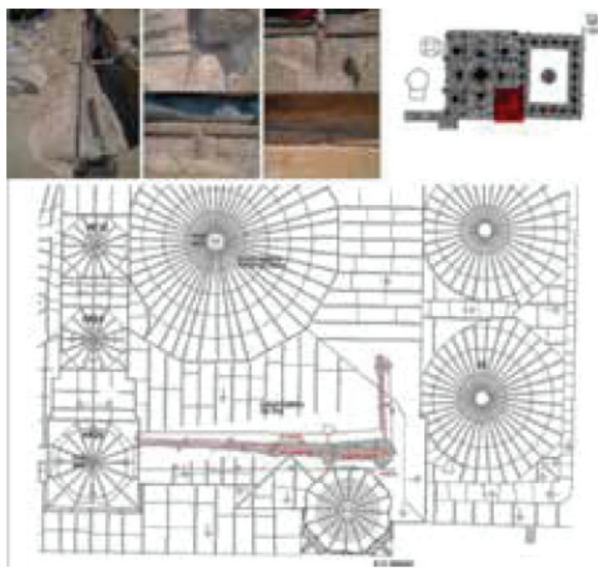

Çizim 3. Dolașmahk kurşun örtüsü altında ortaya çıkan demir hatıl sistemi

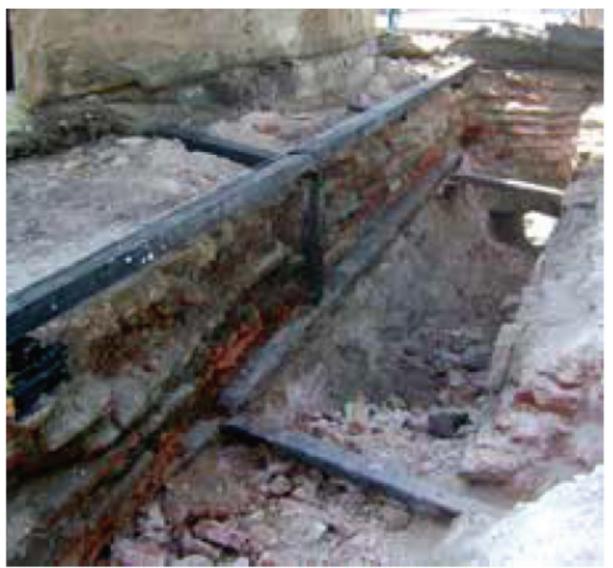

Fotograf 9. Su kanal içinde demir hatıl sistemi

Fig. 7 - Top view from the damaged corner dome next to the main pier station 7 and corroded tension rods changed by new ties to prevent the progressive opening of the main dome [33]. 
Damage mechanisms of the Fatih Mosque from historical large scale events also verify the similar weak structural components as reported in the literature. It is worth mentioning that one compilation [30] describes damage from the 1509 earthquake that was localized at the supporting members of the dome $\left(\mathrm{O}_{1}, \mathrm{O}_{2}, \mathrm{O}_{3}\right.$, and $\left.\mathrm{O}_{4}\right)$ and at the top of the four main piers $\left(\mathrm{O}_{5}, \mathrm{O}_{6}, \mathrm{O}_{7}\right.$, and $\left.\mathrm{O}_{8}\right)$ as shown in Fig. 1. This same collection [30] also describes sequential collapse of the main dome and the main piers during the 1766 earthquake. Fatih Mosque that received damages on several parts by the 17 August 1999 Kocaeli earthquake was restored significantly between 2007 and 2012 [33].

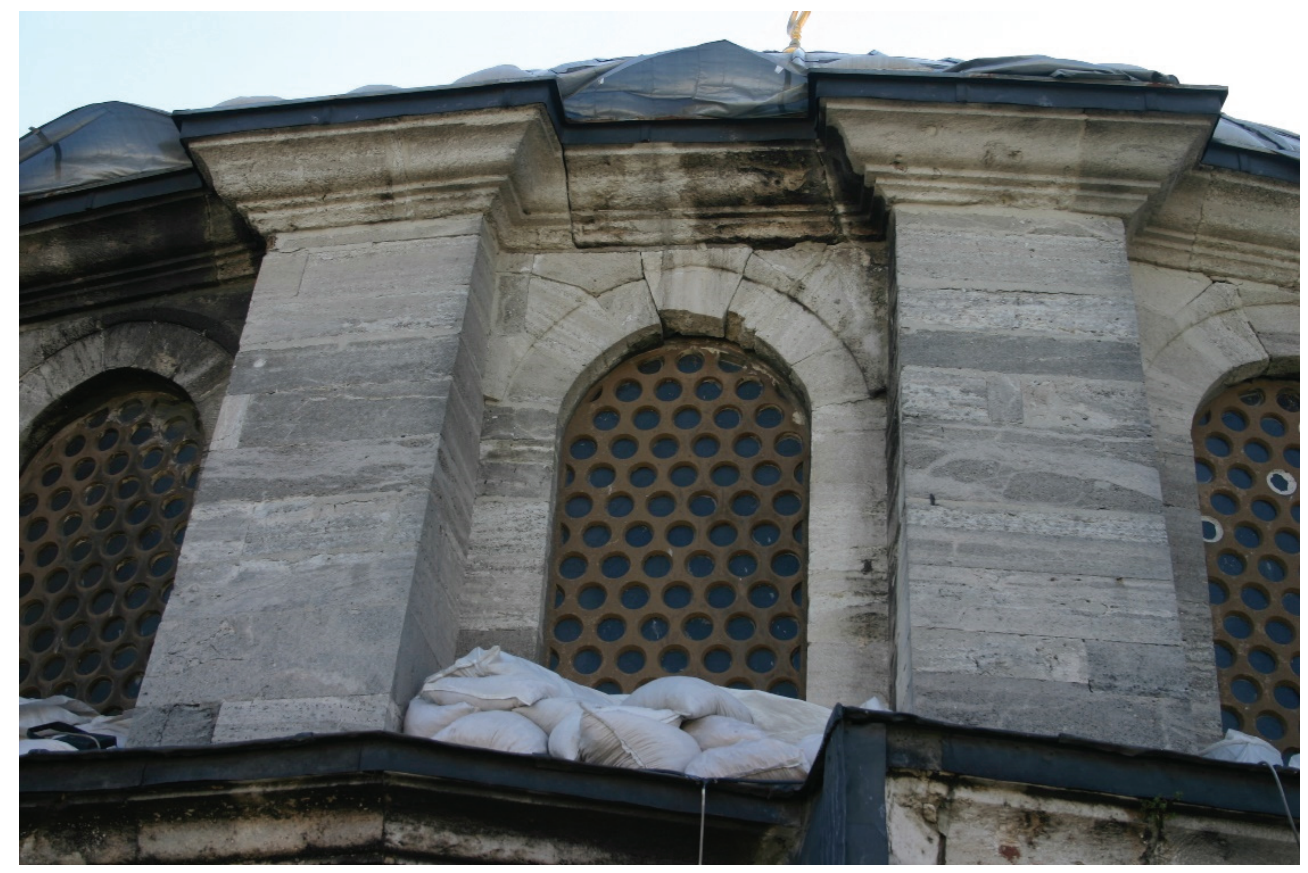

Fig. 8 - Resultant tension cracks around the station 8. Windows were damaged due to tension rod failure causing the dome base to open outwards. Tension rod connection provides horizontal bracing as a diaphragm [34].

\section{THEORETICAL FRAMEWORK}

It is an observable fact that the dynamic system produces responses by modifying the input excitation and the response is not a linear function of the input excitation for most of the structural systems in civil engineering. Therefore, nonlinear behavior is a usual situation rather than the exceptional linear system behavior. Such dynamic systems cannot be identified appropriately by applying physical principles, since complete knowledge of the physical parameters of the structure may not be known; therefore, it is not possible to analytically determine the underlying differential equations. The complexity of the structure on the other hand may preclude an accurate analysis. Remarkably complex dynamic relationships also cannot be described fully in distributed nature in numerical simulations; consequently, simple representative systems like lumped mass are preferred for simulations. 
This article will focus on single-input single-output (SISO) system, since it is the most prevalent and it is tested by several engineering disciplines. The SISO models can be combined also to create multi-input, multi-output (MIMO) and single input multi-output (SIMO) mathematical models for consistency check if necessary. Transfer function estimated from the candidate SISO predictive model may also identify the structural behavior of the test building based on representative lumped-mass model of uncoupled rigid diaphragm floor with single horizontal degree of freedom. The key feature of such simplification corresponds to the full diagonal stiffness matrix with zero off-diagonal terms. Interaction between the stories may also be considered for lumped mass rigid diaphragm floor structure based on SIMO predictive model. Transfer function in this case can be efficient and powerful estimation tool to understand better the performance of a well-balanced stable hyper-static structural behavior. Such story interaction corresponds to the full stiffness matrix with nonzero off-diagonal terms representing contributions/interactions among the stories. All these prediction models can be applicable only for linear and stationary dynamics in accordance with input-output conditions. In case of nonlinearity as well as non-stationarity, Timefrequency $(\mathrm{T}-\mathrm{F})$ algorithms are preferred.

In the study, cross validation is followed using results obtained from both spectral and parametric methods. Characteristic structural transfer functions in parametric approach are estimated from pairs of input-output observations based on two mathematical relationship models, as explained above namely, SISO and MIMO models. The models are linear dynamic systems handling parametric estimations for representative transfer functions that identify all detectable modes from the experimental data streams. The philosophy behind these models is that the global modal properties do not vary noticeably from one FRF to another FRF. Results of this first part that will be discussed in following sections manifest the limits of the linear approaches. On the other hand, advanced analysis techniques such as T-F methods receive considerable attention in case of progressive anomalies or in case of the insufficient physical examination for some parts, which cannot be accessible. Wavelet Transform (WT) and Hilbert Transform with Huang (HHT) (i.e., intrinsic mode functions (IMF)) among available T-F techniques were chosen based on their better performances for complex nonlinearity in nonstationary signals and they may perform more reliable estimations for nonlinear structural properties.

Structural damage detection methods are, in principle, based on the assumption that damage will change the structural properties, which further lead to changes in modal properties. Changes in the modal properties that have important effects on dynamic behavior are used to trace back the causes of large variations in dynamic parameters [37]. Based on practical experiences, another method entails the derivation of the structural stiffness matrix from the experimental modal data [38]. Other techniques for determination of the extent of damage may include Eigen structure assignment [39], probabilistic methodologies [40], matrix perturbation methods [41], and sub matrix approaches in model updating [42]. Recently, estimated Frequency Response Function (FRF) can also be used for feature extraction of a structure and for damage detection in careful systematic studies [43]. FRF estimations based on in-situ measurements are certainly free from extensive numerical errors (in fitting response function, for instance). Within the time domain methods, Complex Exponential (CE), Least-Squares Complex Exponential (LSCE) and the Eigen system Realization Algorithm (ERA) techniques comprise just a few of the most widely used approaches. Among these, ERA with Observer Kalman Identification method (OKID/ERA) [44, 45, 46] 
based on the concepts of the control theory is a more general approach for handling the effect of noise and numerical errors in advanced modal parameter identification techniques.

\subsection{Spectral Method in Damage Identification}

In general, ambient vibration data recorded from historical masonry structures hold low amplitude structural vibration signal and large amplitude wide-band noise. Therefore, in case of damage identification Fourier based spectral methods are usually not suitable for noisy measurements. Time domain system identification technique using test data can be focused on as an alternative. Based on another study [26], it was shown that parametric model estimation fits quite well with the spectral estimation although different data sets recorded in different periods were used. From the discussion, it was evident that the frequency response of the structure and parametric model response provide valuable insight and represent well enough underlying dynamics of the structure if sampling and recording time are suitable [26]. In practice, signals may show nonstationary characteristic and therefore, their frequency content change over time. The advantages of using time-frequency techniques over frequency-domain or time-domain of a signal will be discussed in the following sections.

FRF $(H(w))$ describes the relationship between output response of a structural point $(Y(t))$ and input force history $(F(t))$ at the free field. Eq (1a) indicates that an FRF is defined as the ratio of the FT of an output response $(Y(w))$ divided by the FT of the input force history $(F(w))$ that caused the output. Applying FT to the cross $\left(R_{F Y}\right)$ and auto $\left(R_{F F}\right.$ and $\left.R_{Y Y}\right)$ correlations, spectral density functions $\left(S_{F Y}, S_{F F}, S_{Y Y}\right)$ can be obtain for alternative expressions for the FRF. To minimize the effects of noise on the output, alternatively $H_{l}(w)$ may be defined as seen in $\mathrm{Eq}(1 \mathrm{~b})$ and to minimize the effects of noise at the input, alternatively $\mathrm{H}_{2}(w)$ of $\mathrm{Eq}(1 \mathrm{c})$ may be defined.

$$
\begin{aligned}
& H(w)=\frac{Y(w)}{F(w)} \\
& H_{1}(w)=\frac{S_{F Y}(w)}{S_{F F}(w)} \\
& H_{2}(w)=\frac{S_{Y Y}(w)}{S_{Y F}(w)}
\end{aligned}
$$

It is clearly seen that in the absence of measurement errors, they verify the identity as follow; $H(w)=H_{l}(w)=H_{2}(w)$. To verify the reliability and quality of the measurement, coherence function $\gamma^{2}(w)$ can be tested by the following expression [26];

$\gamma^{2}(w)=\frac{\left|S_{F Y}(w)\right|^{2}}{S_{F F}(w) \cdot S_{Y Y}(w)}$

This indicates how the response is consistent with the excitation. If $\gamma^{2}(w)<0.75-0.80$, quality of the experimental data might be qualified as unreliable in the sense that the signal/noise $(S / N)$ ratio is low. Low values of coherence might be caused from both the presence of high noise or nonlinear behavior of the structure [26]. 


\subsection{Time Domain (OKID/ERA) Method}

OKID/ERA algorithm based on state-space model, coded in Matlab [47] is composed of the following three major computational steps: (1) The observer Markov parameters are calculated with OKID. (2) From the observer Markov parameters, OKID, this time, retrieves the system Markov parameters. (3) ERA is utilized with the system Markov parameters to realize the discrete time state-space $(S S)$ system matrices, $A, B, C$ and $D$. Markov parameters forming the basis for identifying mathematical models are the unit sample response or pulse response histories of the system. In the classical approach, Markov parameters might be extracted from inverse Fourier Transform (IFT) of the frequency response function (FRF), which is defined as the ratio of the Fourier Transforms (FT) of the measured output and input data. Due to aliasing and numerical ill-conditioned problems, calculating accurate Markov parameters in this way is impractical. FT algorithm requiring appropriately long time histories has another disadvantage in calculations. In contrast to the classical technique, OKID finds the Markov parameters more quickly and accurately than FFT-IFFT. Moreover, since OKID has an asymptotically stable observer, influence of the noise and other problems appearing in the estimation of the system Markov parameters from direct input-output data are bypassed. Further details of the theory with derivations are described in Juang [44, 45].

\subsection{Time-Frequency Analysis}

, Dynamic systems may have frequency properties that can change over time or have unusual interruptions or anomalies because of inelastic deformations at different times in their service life. Using the sinusoid type hyperbolic function as the basis, decomposing non-stationary behavior in finite length signal into sinusoids in usual Fourier Transformation (FT) may not capture and properly represent all components of the entire signal and frequency change in time. Fourier transform, $F(w)$ of a time series $f(t)$ and the inverse Fourier transform as seen in Eq. (3) can be obtained by combining the whole signal and this causes to get lost the local features changing with time and frequency. When $F(w)$ is transformed back to time domain, the transformed signal that will repeat itself every time interval $t$ shows no localization in time.

$F(w)=\int_{-\infty}^{\infty} f(t) e^{-i \omega t} d t \quad f(t)=\int_{-\infty}^{\infty} F(w) e^{i \omega t} d w$

The difficulty with localizing frequencies in the spatial domain is one of major weaknesses of the FT in analyzing signals. FT decomposes the signal down to the sinusoids that theoretically extend from minus to plus infinity unlike the wavelet. In contrast, frequency of an irregular and almost non-symmetrical wavelet varies over the length of the waveform and it is better at describing non-stationary problems. By stretching (dilating) and shifting (translating) the waveforms, wavelets that come in various shapes and sizes are used to detect the hidden event and approximate its frequency and location in time. A particular mother wavelet shape that may match or correlates the event unusually well when stretched and shifted suitably may exactly regenerate the whole signal. Even if a wavelet is transformed from time domain into frequency domain, still the relative phase relations of different contributing frequencies determine the position in time. 
Focusing on the localization in time and frequency is at least not the only property that is characteristic about the wavelet transform. Much earlier, short-time Fourier transform (STFT) that is also localized in time and frequency is introduced to overcome the limitations of the FT by Gabor [44] and it provides information about where in time a certain frequency occurs, since it is essentially collection of the FTs applied consecutively onto the windowed (i.e., small) portions of the signal. The signal in the sliding window is assumed approximately stationary. Using the inner product notation, the STFT can be expressed as

$\operatorname{STFT}(\tau, f)=\int x(t) g(t-\tau) e^{-i \omega t} d t$

STFT employs a sliding window function $g(t)$ centered at time $\tau$ of the window. FT is performed on the signal $x(t)$ within the window. Through such consecutive operations, FT of the entire signal decomposes into a two dimensional T-F representation. Recorded field data is generally not known a priori, selection of a suitable window size for effective signal decomposition or for processing nonstationary events in the STFT is difficult. For instance, in contrast to the STFT technique where the window size is fixed and is not suitable for nonstationary data, the wavelet transform enables flexible window sizes in analyzing different frequency components within a signal. By comparing the level of similarities between the signal and a set of patterns obtained from dilating and contracting the original period (i.e., scaling represented by $s$ ) and translating along the time axis (i.e., shifting, $\tau$ ) of a base wavelet $\psi(t)$, T-F characteristic may be mapped remarkably. Using inner product, the wavelet transform (WT) of a signal $x(t)$ can be expressed as;

$w t(s, \tau)=\frac{1}{\sqrt{s}} \int_{-\infty}^{\infty} x(t) \psi^{*}\left(\frac{t-\tau}{s}\right) d t$

where the scaling parameter, $s$ greater than zero, which determines the time and frequency resolutions of the scaled base wavelet $\psi\langle(t-\tau) / s\rangle$. The specific values of $s$ are inversely proportional to the frequency. The symbol $\psi^{*}(\cdot)$ denotes the complex conjugate. WT is capable of extracting the inherent components within time series over its entire spectrum, by using small scales (corresponding to higher frequencies) and large scales (corresponding to lower frequencies) for decomposing frequencies.

The Hilbert-Huang transform (HHT), developed by Huang et al. [48] as an empirical approach, may also solve the nonstationary structure. The HHT consists of self-adaptive empirical mode decomposition (EMD) and Hilbert spectral analysis (HSA). Steps are summarized below and details may found in Huang et al. [48]. The EMD was designed based on the assumption that the data set consists of simple different intrinsic mode functions (IMF) of oscillations with harmonic or nonsinusoidal coexisting characteristics derived recursively from the data. First mean $m_{l}$ is calculated and subtracted from the whole data, $X$ and difference $h_{l}$ called IMF candidate as a first component since it satisfies all the conditions of an IMF as detailed in Huang et al. [48].

$h_{1}(t)=X(t)-m_{1}(t)$

However remaining data $h_{l}(t)$ that is treated as the recent data and previous process, called the sifting, is repeated; 
$h_{11}(t)=h_{1}(t)-m_{11}(t)$

In this case, $m_{1 l}$ becomes mean of the upper and lower envelopes of $h_{1}$. Consequently, other rounds of sifting process are carried out $k$ times until the residue becomes constant (monotonic) or represents an negligible trend (baseline passing from zero at most two times).

$$
\begin{aligned}
& h_{1 k}(t)=h_{1(k-1)}(t)-m_{1 k}(t) \\
& c_{1}(t)=h_{1 k}(t)
\end{aligned}
$$

Then the recent $h_{1 k}(t)$ is nominated as the first IMF component $c_{l}$, which contains highest frequency content of the signal $X(t) . c_{1}$ is removed from the data $X(t)$ to obtain the residue $r_{l}$, which contains lower frequency components. The $r_{l}$ is treated as the new data and subjected to the same sifting process. This procedure is repeated to obtain all the subsequent $r_{i}$ functions;

$$
\begin{aligned}
& r_{1}(t)=X(t)-c_{1}(t) \\
& r_{i}(t)=r_{i-1}(t)-c_{i}(t), \quad i=2,3,4, \ldots \ldots, n
\end{aligned}
$$

After completing the decomposition, the original signal can be collected by summing $n$ IMF components plus the final residue.

$X(t)=\sum_{i=1}^{n} c_{i}(t)+r_{n}(t)$

In HSA, signal $c_{i}(t)$ and its $H T, H\left[c_{i}(t)\right]$ can be combined to form the analytical signal $Z_{i}(t)$ in a complex structure,

$Z_{i}(t)=c_{i}(t)+j H\left[c_{i}(t)\right]=a_{i}(t) e^{j \theta_{i}(t)}$

and HT is defined as

$H\left[c_{i}(t)\right]=\frac{P}{\pi} \int \frac{c_{i}(u)}{t-u} d u$

where $P$ denotes the Cauchy principle value. With this newly defined analytical signal, timedependent $a(t)$ and phase $\theta(t)$ become observable over the time and the instantaneous frequency can be defined as,

$$
\begin{aligned}
a_{i}(t) & =\sqrt{c_{i}^{2}(t)+H\left[c_{i}(t)\right]^{2}} \\
\theta_{i}(t) & =\arctan \frac{H\left[c_{i}(t)\right]}{c_{i}(t)} \\
w(t) & =\frac{d \theta(t)}{d t}
\end{aligned}
$$


Applying the HT to the $n$ IMF components of $\mathrm{X}(\mathrm{t})$ but excluding residue $r_{n}, \mathrm{X}(\mathrm{t})$ can be written in terms of amplitude and instantaneous frequency corresponding to each component $i$ as functions of time.

$X(t)=\Re \sum_{i=1}^{n} a_{i}(t) e^{j \int w_{i}(t) d t}$

Eq. (14) differs from the time-independent amplitude and phase in the FT. It improves the flexibility of the expansion and tracks the nonstationary characteristic. The T-F distribution of the amplitude called as the Hilbert spectrum $H(w, t)$ defined as

$H(w, t)=\sum_{i=1}^{n} \widetilde{H}_{i}(w, t)=\sum_{i=1}^{n} a_{i}(t)$

Where $\widetilde{H}_{i}(w, t)$ stands for $i$ th component of the total Hilbert spectrum $H$. The square of $H$ also gives the energy distribution (i.e., energy density). Another very important definition is the marginal spectrum $h(w)$ provides a measure of total amplitude contribution from each frequency, in which $T$ denotes the time length of the signal.

$h(w)=\sum_{i=1}^{n} \tilde{h}_{i}(w)=\sum_{i=1}^{n} \int_{0}^{T} a_{i}(t) d t$

\section{DESCRIPTION OF THE INSTRUMENTATION AND DATA PROCESSING}

Sensor locations was decided by first performing analytical modal analysis and then it was finalized based on modal participation factors of the candidate observation points in the mode shapes according to preliminary observations (i.e., test data). Structurally important eight observation points were instrumented by two-component seismometers for principal horizontal directions to track the global behavior of the superstructure and one was used at the basement to capture the true structural input characteristics, as seen in Fig. 1, and described in Table 1. Another one records the free field motion as micro-tremors at the far site in the courtyard. Deciding seismometer as a sensor type was motivated by the experiences from past experimental studies, it is certain that the velocity peaks of low frequency input motion (i.e., accelerating momentums in free vibration) have high impact on structures. Structural response is also directly related to the input energy, which is proportional to the velocity. Naturally, low frequency signals give dominant low frequency content but non-stationarity may be introduced. The equipment used for the measurement and the data acquisition are as follows; Analog to digital converter, DT-2827 A/D board with 16 bit A/D converter at the speed of $100 \mathrm{KHz}$ accommodating both single-ended and differential analog inputs, manufactured by Data Translation Inc., Multiplexer card, DI-64x4V2 manufactured by Quesing Electronics, accepting up to 64 channels at $1000 \mathrm{~Hz}$ sampled data and signal conditioner, SC-1 manufactured by Kinemetrics. From Mark products, L22 type low frequency seismometers, with peak-to-peak 0.15 -inch amplitude precision, were utilized for the tests. Allowable accuracy of the synchronic acquisition was examined in detail on the site and adjusted at a sampling rate of $122 \mathrm{~Hz}$ through the A/D converter. Four sets of ambient vibration measurement were recorded for 5 minutes from structure and the courtyard for test and verification purposes. The calibration measurement was performed at the basement right after collecting structural data by collocating instruments next to each other 
parallel to the structural axes. Control test data were utilized for qualifying linearity and distortion in recordings based on wavelet analysis. Finally, band pass filtering was decided between frequencies of $0.1 \mathrm{~Hz}$ and $50 \mathrm{~Hz}$ (as the Nyquist frequency band) to eliminate the effects of white noise, hardware problems and effects of the different cable lengths. Baseline correction (linear and nonlinear if necessary) and re-decimation for eliminating high frequency spikes in the record were also performed when they were needed. Ambient displacement time histories of the structural points are plotted on the same scale for the same time window for SE-NW direction, as a typical example shown in Fig. 9.

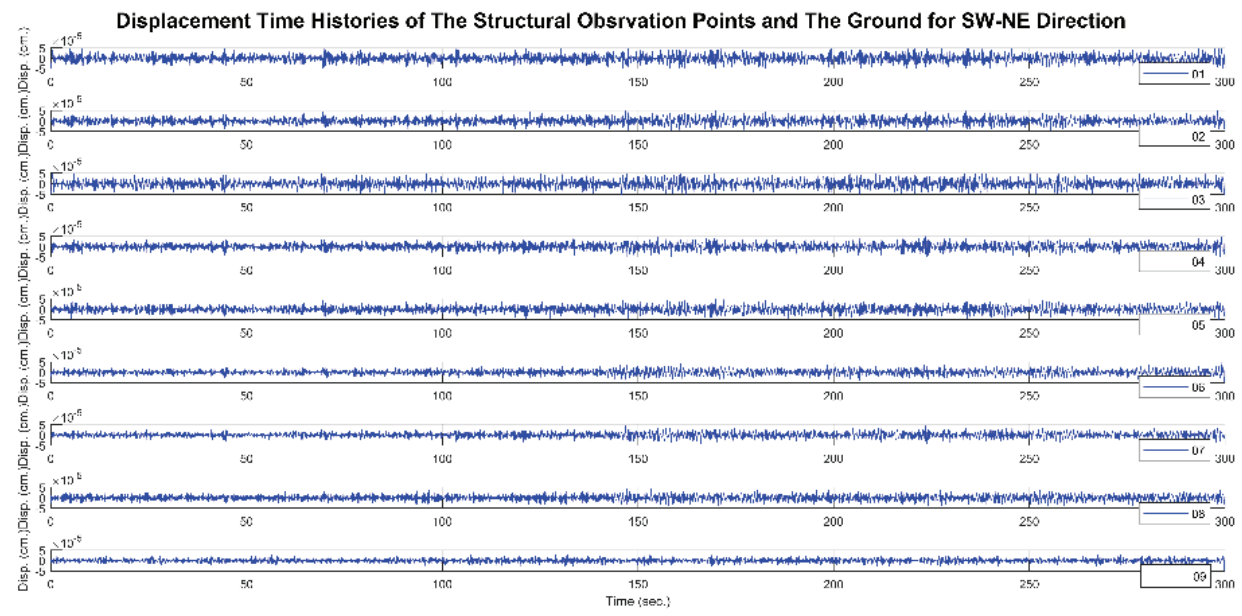

Fig. 9 - Displacement time histories for the structural observation points $O 1$ through $O 8$ and ground station $\mathrm{O} 9$ for $\mathrm{SE}-\mathrm{NW}$ direction.

\section{ANALYSIS OF THE RECORDINGS}

In this section, first tradational approaches from frequency domain and time domain are performed to illustrate that linear-and-stationary data analysis provides incomplete or biased information for damage detection. Then, wavelet and HHT analysis from T-F techniques are adopted to demonstrate logic and direct information in damage identification. Matlab implementations of the all algorithms used in this study have been developed since 1990s using Matlab macro scripts [47].

\subsection{Nonparametric (Spectral) Analysis}

Instrumentally corrected records were Fourier transformed and to reduce the undesired noise components the power spectra for SE-NW direction is plotted in Fig. 10. Stations 1 and 3 $\left(O_{1}, O_{3}\right)$ yield larger spectral amplitudes in both low and high frequency regions but in global region such extraordinary amplitudes are not observed. Some other sharp peaks are seen at $24 \mathrm{~Hz}$ for $O_{3}$ and around $38 \mathrm{~Hz}$ for $O_{1}$. 


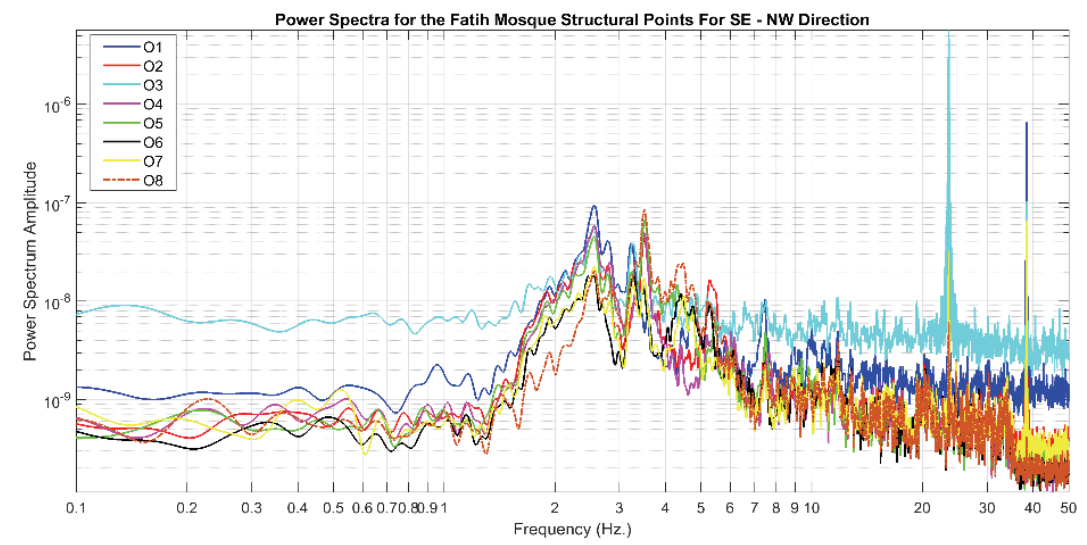

Fig. 10 - SE-NW component power spectra for the structural observation points.

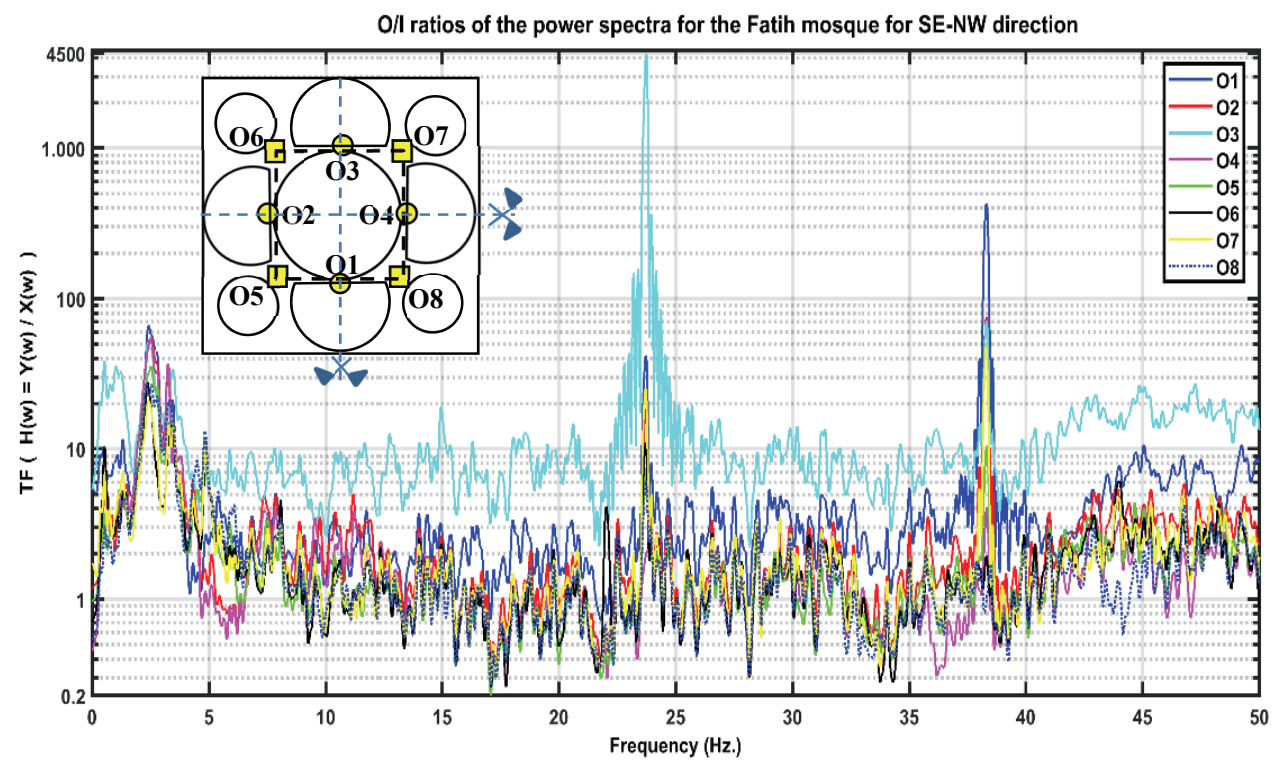

Fig. 11 - Spectral transfer functions for SE-NW direction between structural responses and base input motion (defined by the expression in Eq. (1)).

In Fig. 11, spectral transfer functions for SE-NW direction between structural responses and reference base input motion have been calculated as defined by the expression in Eq. (1). Spectral peaks at the cornice-level stations at the four springing points of the main arches $\left(\mathrm{O}_{5}, \mathrm{O}_{6}, \mathrm{O}_{7}, \mathrm{O}_{8}\right)$ and those at the crowns of the main arches at the dome-base $\left(\mathrm{O}_{1}, \mathrm{O}_{2}, \mathrm{O}_{3}, \mathrm{O}_{4}\right)$ are seen almost at the global frequencies. Stations $O_{3}$ and $O_{1}$ that envelope the others in the all frequency range have two broadband peaks with high amplitude values of 30 and 10 at around $1.2 \mathrm{~Hz}$ and $1.8 \mathrm{~Hz}$, respectively, while other stations oscillate at around 1 in low 
frequency region. In the high frequency region, around $24 \mathrm{~Hz} \mathrm{O}_{3}$ and around $38 \mathrm{~Hz} \mathrm{O}_{1}$ has sharp peak. Such peaks that may be sign of coherence with ground input motion can also indicate local failure. This is not the case for other stations. In Fig. 12, magnitude squared coherences $\left(\gamma^{2}(w)\right)$ between the structural responses and the input motion are calculated for SE-NW direction. Average value little exceeds the critical value of 0.75 and rises to 0.8 that indicates that the $S / N$ ratio is acceptable for linear analysis but it might be also noteworthy sign for the nonstationarity and nonlinearity. In another study [26], de-noising procedure was applied to test data sets to reconstruct the original signal based on the orthogonal wavelet packet decomposition procedure. Close estimation was observed and it is concluded that the reconstructed signal with retained energy of $82 \%$ appears reasonable and consistent for the purpose of a linear analysis [26].
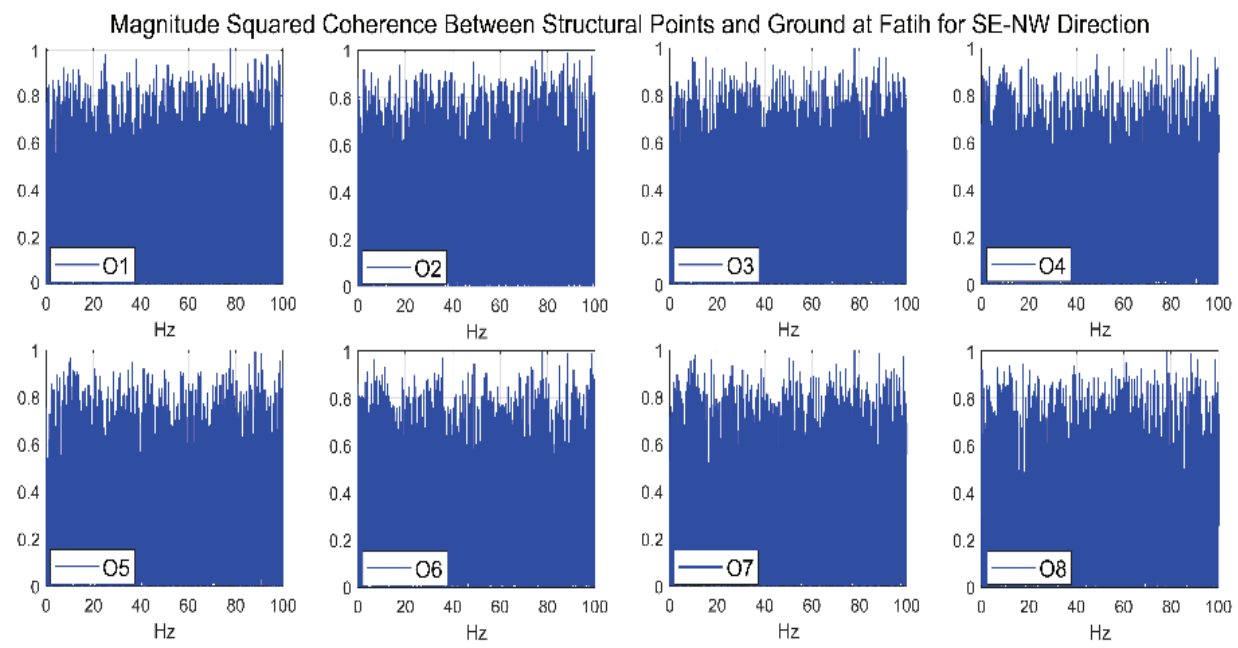

Fig. 12 - Magnitude squared coherences between the structural responses and the input motion (defined by the expression in Eq. (2)) for SE-NW direction.

As a last application, short time Fourier transform (STFT) was performed to compute a timevarying spectrum by applying FT to a windowed section of the data. STFT provides timelocalized changes in frequency with limited precision and somehow reduces the nonstationarity but the window size influences the temporal or frequency resolution of the analysis. Selection of the window length is subjective and needs many trials dependent on features of interest. STFT spectra are estimated in Fig. 13, applying Kaiser window for smoothing. In smoothing, the energy in the main lobe of the window is maximized relative to total energy. As seen in T-F plot, nonstationary characteristic can be observed on all observation points. However, at stations $O_{1}$ and $O_{3}$, two sharp spikes at $24 \mathrm{~Hz}$ and $38 \mathrm{~Hz}$ are developed exceptionally and they almost keep the linearity throughout. Key block failure at $\mathrm{O}_{3}$ and partial damage at $O_{1}$ may cause high frequency peaks indicating local damages. Due to poor redundancy, damage may destabilize the adjacent members in the SE- NW direction. This is seen globally on some neighbor members such as at $O_{2}$ and $O_{7}$ strongly and at $O_{6}$ slightly. Results of the conventional approaches are summarized for this section, as follows: 
although there are small individual differences in the amplitudes of the transfer functions, for SE-NW direction, global spectral peaks are observed at $\sim 2.5,3.5,4.3$, and $5.3 \mathrm{~Hz}$ as seen from Fig. 11. It is obvious that station $O_{3}$ with superior amplitudes and station

STFT Spectograms of the Ambient Measurements at the Fatih Mosque for NS Direction
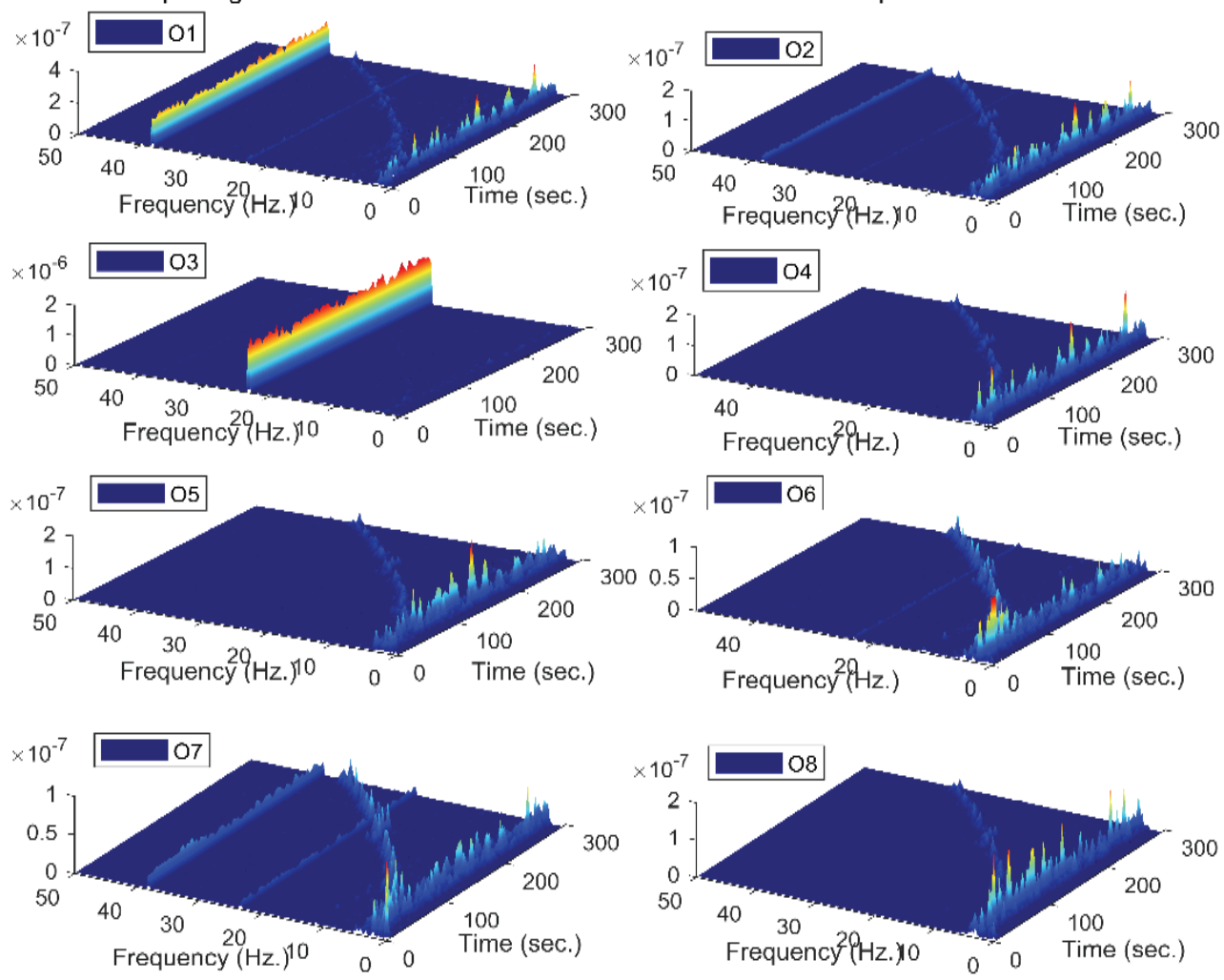

Fig. 13 - STFT of the records at the eight observation stations for SE-NW direction.

$O_{1}$ with relatively large amplitudes behave differently in both low and high frequency regions when compared within the group of other similar observation points. Such inconsistencies can be considered as signs of damage and may be explained only by the damage that occurred during the August 17, 1999 Kocaeli earthquake. For instance, close inspection at the crown station $\mathrm{O}_{3}$ verified the damage by large cracks around the key point of the arch and above as seen in Fig. 2. In general, the response spectrum or Fourier based transfer functions provide average information such as influence of the input motion on structure with different frequencies, which the structure have different sensitiities. From such spectrait is impossible to determine which factors or features of the motion contribute most to damage. Therefore, transfer functions or response spectra based measures are essentially just an alternative representation of Fourier spectra. 


\subsection{Parametric Analysis}

OKID-ERA technique [44, 45] was adopted for single input-multi output pairs (SIMO) and multiple excitations and responses (MIMO) in this experimental modal identification study. As seen from transfer functions for SE-NW direction in Fig. 14, different levels of distinguishable peaks are derived from SIMO and MIMO models. SIMO model captures the important peak frequencies with sufficient accuracy, but magnitudes are arguably small. Responses at the stations $O_{1}, O_{2}$, and $O_{4}$, located at the crowns of the main arches, display almost the same peak magnitudes at the same frequency of $2.5 \mathrm{~Hz}$ for the SE-NW direction; station $\mathrm{O}_{3}$ (which possesses several peak amplitudes at smaller frequencies, $0.4 \mathrm{~Hz}, 1.2 \mathrm{~Hz}$, $1.8 \mathrm{~Hz}$ and $2 \mathrm{~Hz}$ ) is exceptional and indicative of an anomaly. Dominant frequencies of the structure estimated by SIMO and MIMO systems are close to each other although peaks of the MIMO with closely spaced modes spread over broader bands. In the MIMO model, similar to the SIMO model, $\mathrm{O}_{3}$ yields an early peak at $1.2 \mathrm{~Hz}$ before the first global modal frequency. Same peak frequencies with different TF amplitudes for the SE-NW direction are also concluded from spectral analyses as seen in Fig. 11. Furthermore, station 3 among the crown stations exceptionally yields several early peaks as observed in parametric TFs of Fig. 14. These techniques may not always produce similar results because MIMO is more suitable for large complicated structures. However, this bisymmetrical structure yields very close results when comparing the extracted modal parameters from these techniques. All analyses up to now, namely, spectral, parametric SIMO and MIMO models yield almost consistent results for station $\mathrm{O}_{3}$ alarming serious structural damage in SE-NW direction. Similarly, station $O_{1}$ also has damage susceptibility in SE-NW direction. Only minor peak shifts to lower frequencies show poor damage detection results. It is shown that non-parametric estimation qualified quite well with the results of the parametric model. From the discussion, it is evident that both estimation techniques provide valuable insight and represent the underlying dynamics of the structure. Using several validation data sets, identified model was tested in this part to investigate the inherent differences and similarities in dynamic response of the identical members of the structure. However, most frequency and time domain filters are linear, if the waveforms in the data were distorted by nonlinear progression; the band pass type operations could only pick up the fundamental characteristic and exclude all the necessary different waveforms, which can be important components to reconstruct the full waveforms. This drawback may cause poor results and incorrect interpretations for the damage detection.
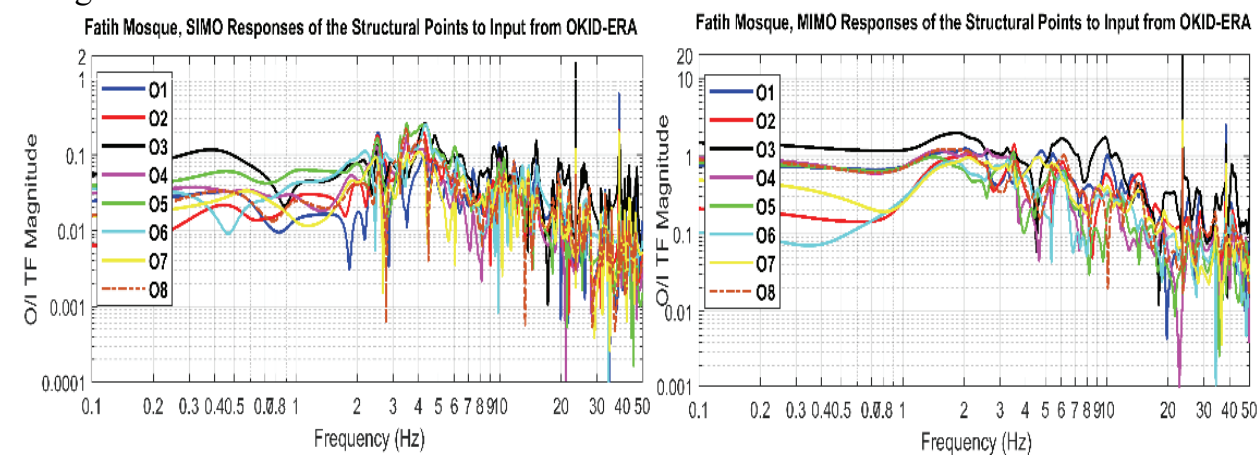

Fig. 14 - Transfer functions of the structural observation points estimated from SIMO (left) and MIMO (right) systems for SE-NW component. 


\subsection{Time-Frequency (T-F) Analysis}

For the ambient data that was only low-pass filtered at Nyquist frequency, T-F spectra are estimated using wavelet theory for each direction. There is no unique wavelet-base form, which can satisfy the requirements in such an analysis. A number of different wavelet families are tested to extract the recognizable features for damage detection. It was found that the so-called bump and Mexican hat wavelet bases [47] are the most successful at identifying the damage at a similar level of performance; finally, the bump wavelet is decided for this study. It is decided that local jump in the wavelet coefficients points out the location of the damage. Cross-examination of the T-F spectra among the stations can reveal localized similarities otherwise local increases in the absolute value of the wavelet coefficients may show nonstationary power in T-F plane. When the zone has become full of high wavelet coefficients, nonlinear behavior becomes practical due to the interferences of the broken sides at the damage point and interactions between the adjacent components. Crown station $\mathrm{O}_{3}$ in Fig. 15 shows linearity throughout the recording with complete high power at around $24 \mathrm{~Hz}$ in broadband characteristic. Severe damage at $\mathrm{O}_{3}$ causes such linearity and loosens the bonds between the stones around the key block. Other stations that generate almost similar energy distributions in T-F domain exhibit nonlinearity-non-stationarity and this tendency increases as the time and frequency progress. T-F spectra with energies as scaled in the color bar manifests that the energy flows from low to high frequencies. Transverse cracks and openings developed around the key block form the third hinge disrupting monolithic behavior and responding individually at its local frequency of $24 \mathrm{~Hz}$ throughout the recording. Another crown station $O_{l}$ also shows close non-monolithic behavior at the local frequency of $38 \mathrm{~Hz}$ (stiffer therefore slight damage). Other structural members of this low redundant system display nonstationary-nonlinear behavior under the effect of the accumulated damages. For example, station 2 is affected strongly by the anomalies of both forms, namely, stationarylinear and non-stationary-nonlinear appearances as seen at stations 1 and 3, due to opening dome base (see Figures 3). Especially neighbor stations $O_{6}$ and $O_{7}$ located at the springing points of the arch $\left(\mathrm{O}_{3}\right)$ and other neighbor stations $O_{5}$ and $O_{6}$ located at the springing points of the arch $\left(\mathrm{O}_{2}\right)$ are strongly affected due to tension rod connection (providing horizontal bracing as a diaphragm) failure causing the dome base to open outwards (see Figure 5,6 and 7). Records of the stations 4 and 8 reflect only low-level nonstationary features manifesting little effects from neighbors in touch. Another characteristic of the T-F spectra is that the wavelet coefficient peaks increasing continuously by the time and reaching their maxima at the end of the recording correlate with each other as well. Many types of signals in practice may be non-sparse in the Fourier-based analysis became detectable in T-F domain as seen in Fig. 15 and 16. It is well known that coherence on a scale from 0 to 1 is a current practice for evaluating the linear correlation between two stationary processes in frequency domain to detect any pattern in the signals in relation with each other. Similarly, wavelet-based coherence provides time-varying correlation as a function of frequency. By using the wavelet coherence (WTC), ambient measurement data set is examined for the structure-basement (ground) system to extract regions in T-F space where the two time histories co-vary (but does not necessarily have high power). The WTC results based on the structural vibration and ground data have maxima around 1 (i.e., nearly perfect agreement) approximately after $50 \mathrm{~Hz}$. Additional maxima, characterized by several broadband peaks, close to 1 are distributed pretty equally between the band of $20 \mathrm{~Hz}-40 \mathrm{~Hz}$ for the station $3, \boldsymbol{O}_{3}$. 


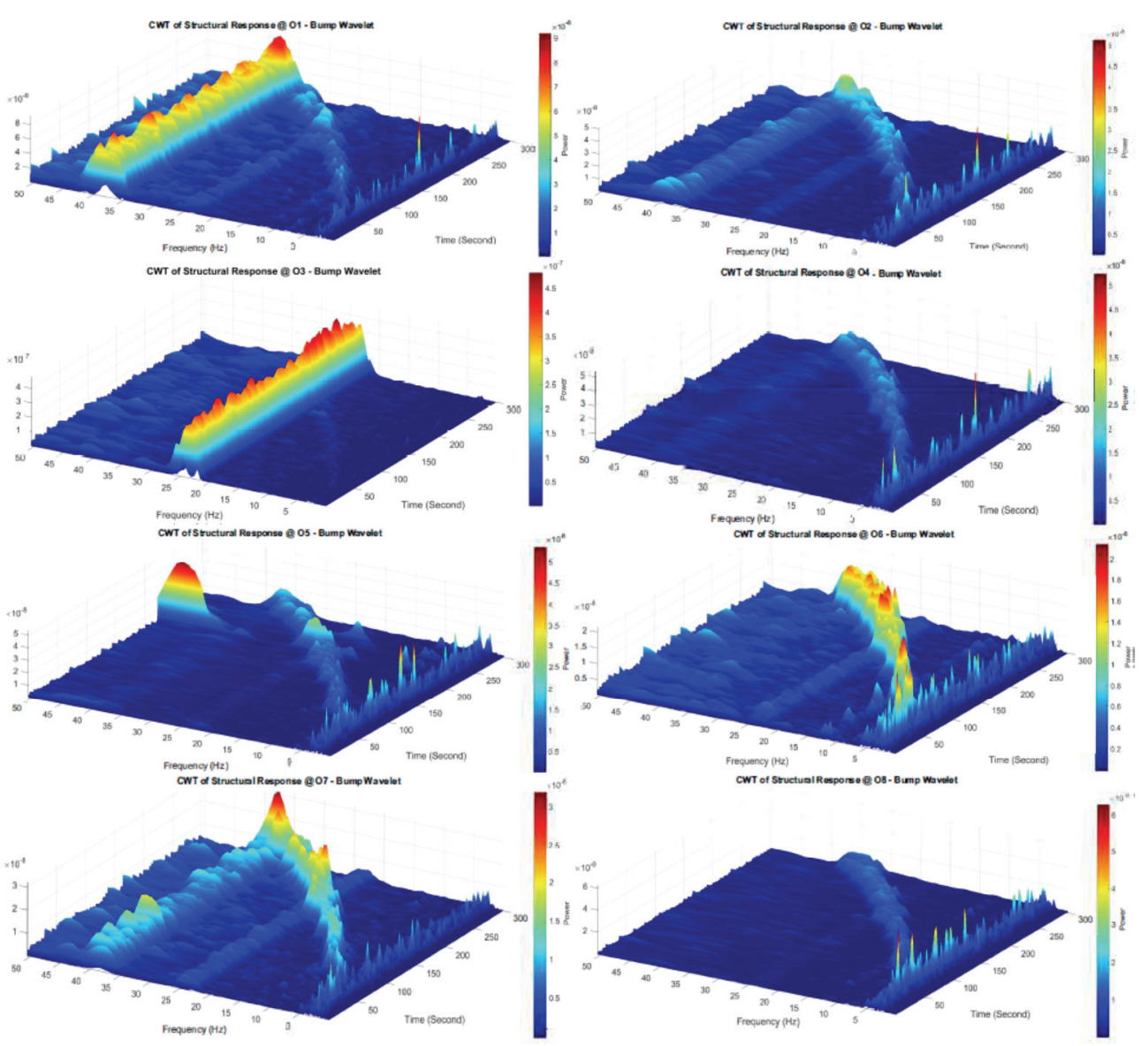

Fig. 15 - Continuous Wavelet Time-Frequency spectra of the structural observation points of the structure estimated for SE-NW component.

The dominant maxima corridor that can be easily recognized, corresponding to the linearity as indicated by the WT spectra in Fig. 15, keeps the highest coherence monotonically for all the recording time while almost the other stations in the considered part show many brief increases in coherence accompanying by significantly high values of 0.7 .

On the other hand, cross wavelet transform (XWT) finds regions in T-F space where the time series show high common power. It is intensely seen from Fig. 17 that the cross correlation of the wavelet coefficients for SE-NW direction have high common power practically in a linear fashion between the free field microtremor (as a reference data for linearity) and stations $\boldsymbol{O}_{1}$ and $\boldsymbol{O}_{3}$. Comparison of cross correlation and coherence results differed intensely and cross correlation recognizes the relationship to a significant statistical degree whereas the coherence method showed weakness in recognizing the linear association. 

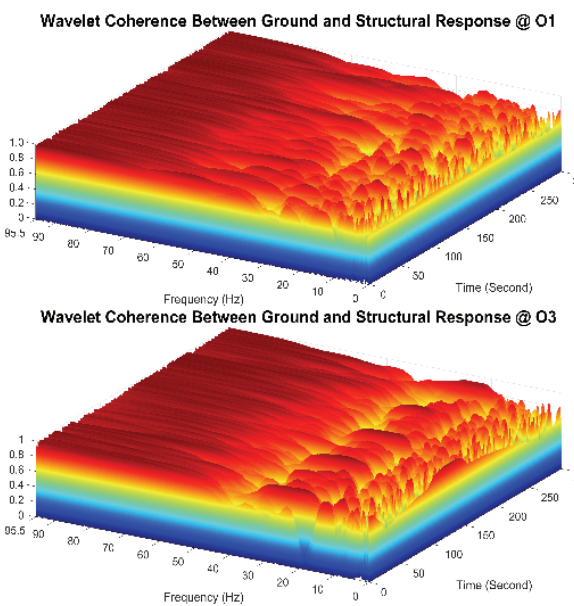

Wavelet Coherence Between Ground and Structural Response @ O5

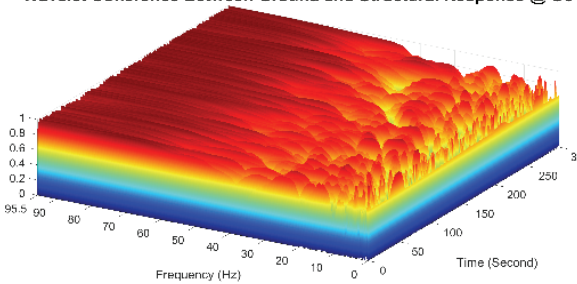

Wavelet Coherence Between Ground and Structural Response @ 07

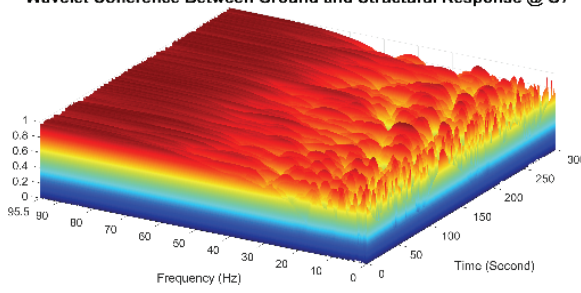

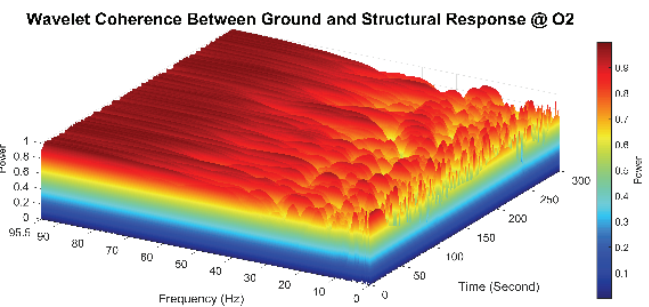

Wavelet Coherence Between Ground and Structural Response @ 04

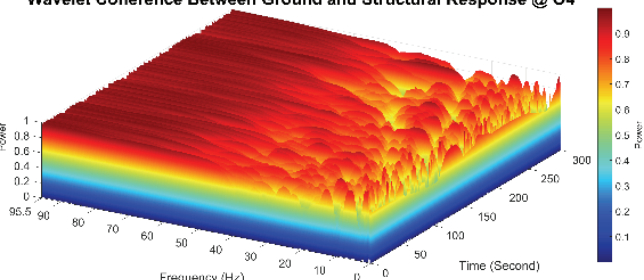

Wavelet Coherence Between Ground and Structural Response @ 06

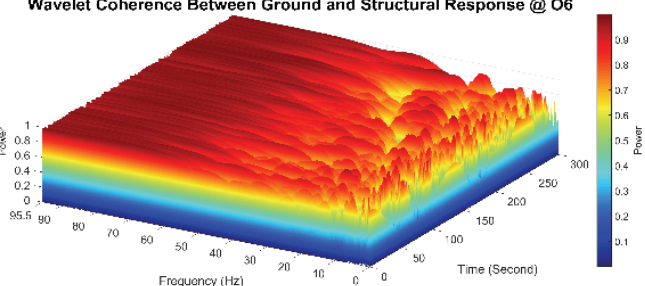

Wavelet Coherence Between Ground and Structural Response @ 08

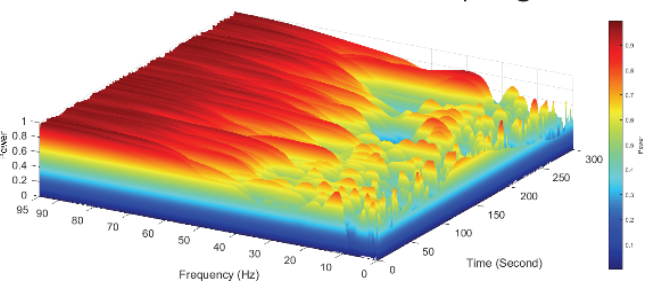

Fig. 16 - Wavelet coherence in Time-Frequency space for the structural responses and basement input motion for SE-NW component.

A survey of Hilbert Huang analysis as well as their suitability in T-F mapping will be presented in this last part. A comparative study carried out to show the performance and accuracy of the two recent methods of T-F analysis for damage assessment. Conventional data preprocessing techniques might hide valuable information or distort the recordings. In contrast, a new method, which prevents the degradation, namely EMD is adopted here. The EMD technique leads to physically meaningful decompositions. As we shall see from Fig. 18, EMD can extract valuable characteristics of the vibrations with just a few IMF components. IMF with higher frequency content could be identified as being generated by a local instability. After member capacity exceedance or dislocations of the stones around the key block of the arch, localized plastic hinge is developed that reduces the level of redundancy and weakens the structural rigidity. As a result of this, flexibility of the 


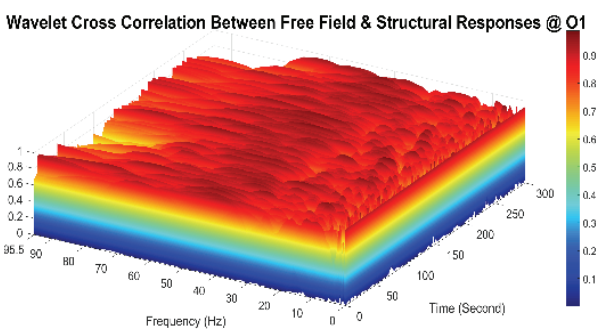

Wavelet Coherence Between Free Field and Structural Responses @ 01

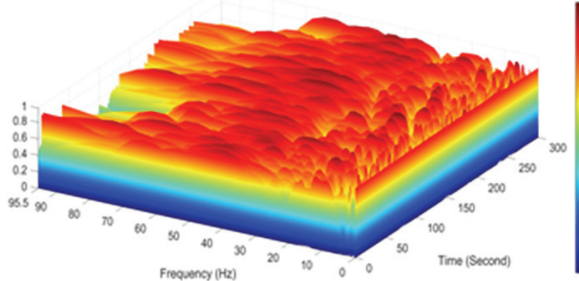

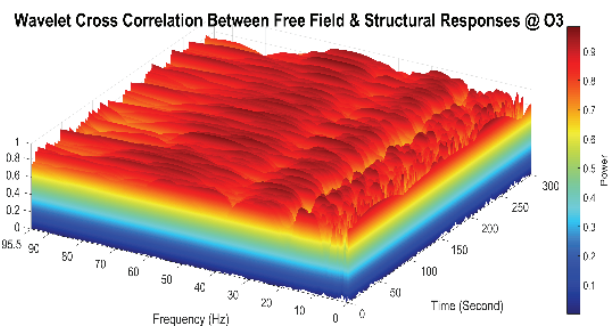

Wavelet Coherence Between Free Field \& Structural Responses @ 03

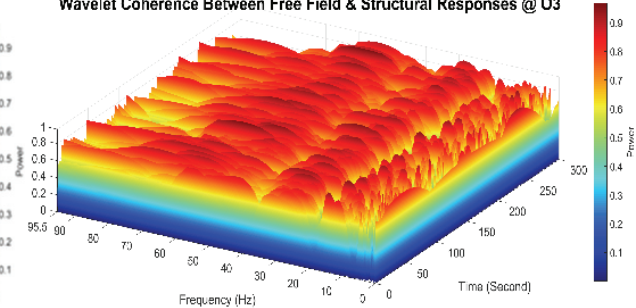

Fig. 17 - Top row, cross correlation of the WT coefficients; second row coherences of the $W T$ coefficients for the free field microtremor and the stations 1 and 3 for SE-NW component.

structural system will be increased in a reverse manner and this lowers the vibration frequency. As seen in Fig. 18, IMFs start with the highest vibrations and slow down to the small frequency oscillations. Vibrations developed around the average dominant frequency starting from $38 \mathrm{~Hz}$, down to $24 \mathrm{~Hz}, 19 \mathrm{~Hz}, 12 \mathrm{~Hz}, 4 \mathrm{~Hz}, 2.5 \mathrm{~Hz}, 1.5 \mathrm{~Hz}$ and $1 \mathrm{~Hz}$ for the first 8 IMFs respectively. Instant T-F spectra of the HHTs for the entire ambient vibrations recorded at the 8 stations are plotted with the peak points in Fig. 19. The color scales next to the T-F plots illustrate the level of spectral power. Contribution of each frequency component in the instantaneous frequency vectors of the IMFs is clearly seen for top four for arch stations $\left(O_{1}\right.$, $\left.\mathrm{O}_{2}, \mathrm{O}_{3}, \mathrm{O}_{4}\right)$, lower four for column stations $\left(\mathrm{O}_{5}, \mathrm{O}_{6}, \mathrm{O}_{7}, \mathrm{O}_{8}\right)$. all the time stations. As distinguished from Fig. 19, some frequencies are never reached in some IMFs. Therefore, zero contribution to the system dynamics from some frequencies can be noticeable. Comparison of individual CWT spectra of the identical stations from Fig. 15 and 16, and likewise comparison of the corresponding HHS of the IMFs extracted from lightly damaged station $O_{1}$ in Fig. 20 clearly show that the presence of nonlinearity adds considerable complexity to the frequency response characteristics of the system. Measures of this complexity relative to the undamaged or lightly damaged structural response can be visible signs of failure at its onset as proposed in an earlier study of Beyen [26]. Furthermore, for nonstationary and nonlinear nature of a low redundant structure with serious damage, Fourier based response spectrum cannot represent accurate low frequency energy particularly when the signal is highly nonstationary because superposition of the linear Fourier decomposition with endless energy generates artificial high frequency harmonics. Therefore, energy spectra obtained from both techniques reveal such differences. However, when the FT is applied on to the IMFs, which were decomposed based on Huang [48], nonstationary-nonlinear characteristics, if they exist, become very distinguishable from FAS plots. As a typical example, such information for the station $8\left(O_{8}\right)$ can be easily inferred from Fig. 21 when 
compared first four FAS of the IMFs. Nonstationary-nonlinear characteristics strongly manifest the existences in the first and second IMFs. Non-stationarity in the IMF-1 starts after $150 \mathrm{sec}$. and increases continuously through the recording in high frequency region between $20 \mathrm{~Hz}$ and $40 \mathrm{~Hz}$. Same behavior is also seen in the IMF-2 but amplitudes decrease as the time increases. IMF-3 and IMF-4 show somehow linear time frequency variations. Based on this coherence, in order to compensate the lack of non-stationarity in Fourier transformation, it is recommended to decompose the signal based on Huang [48] before applying Fourier Transform for particularly nonstationary dynamics.

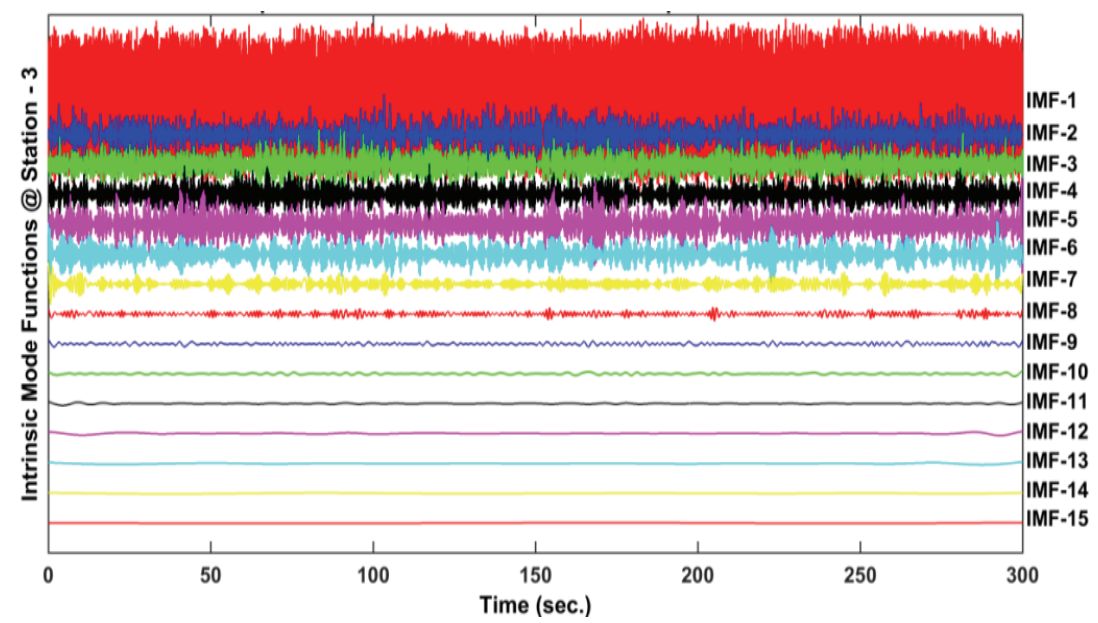

Fig. 18 - IMFs of the station - $3\left(\mathrm{O}_{3}\right)$ responses for SE-NW component based on EMD with adaptive noise.

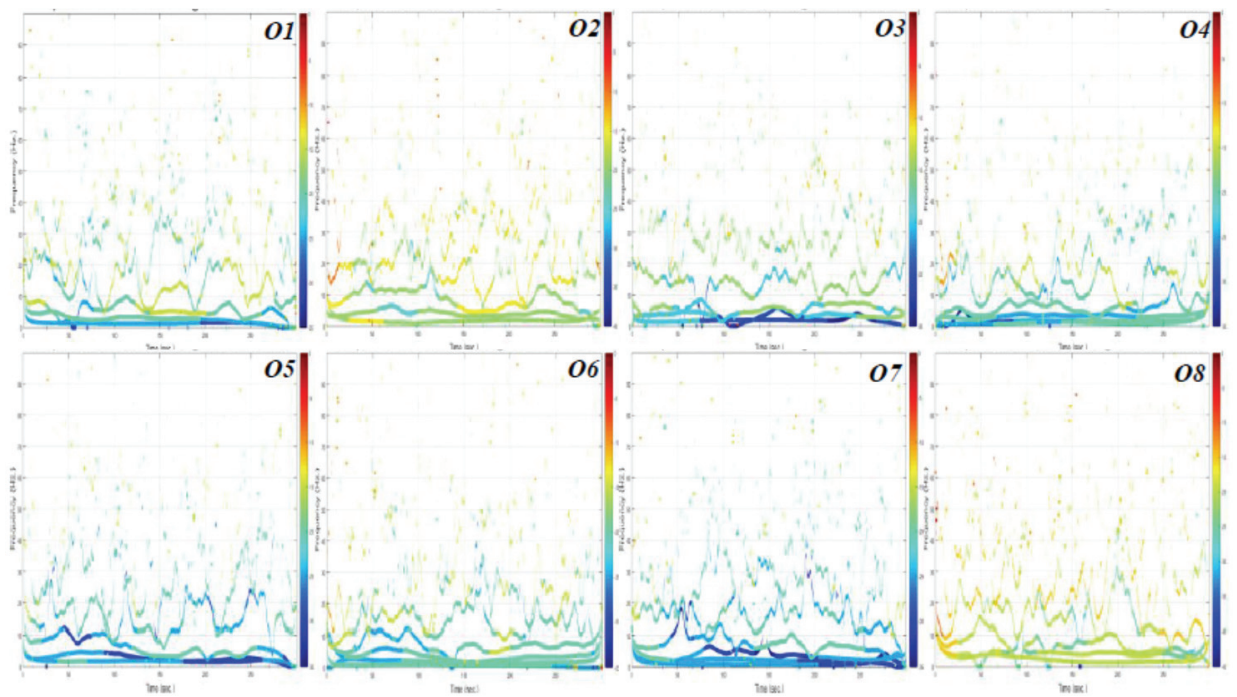

Fig. 19 - HS peak points of all the IMFs decomposed from 8 stations for SE-NW component. 

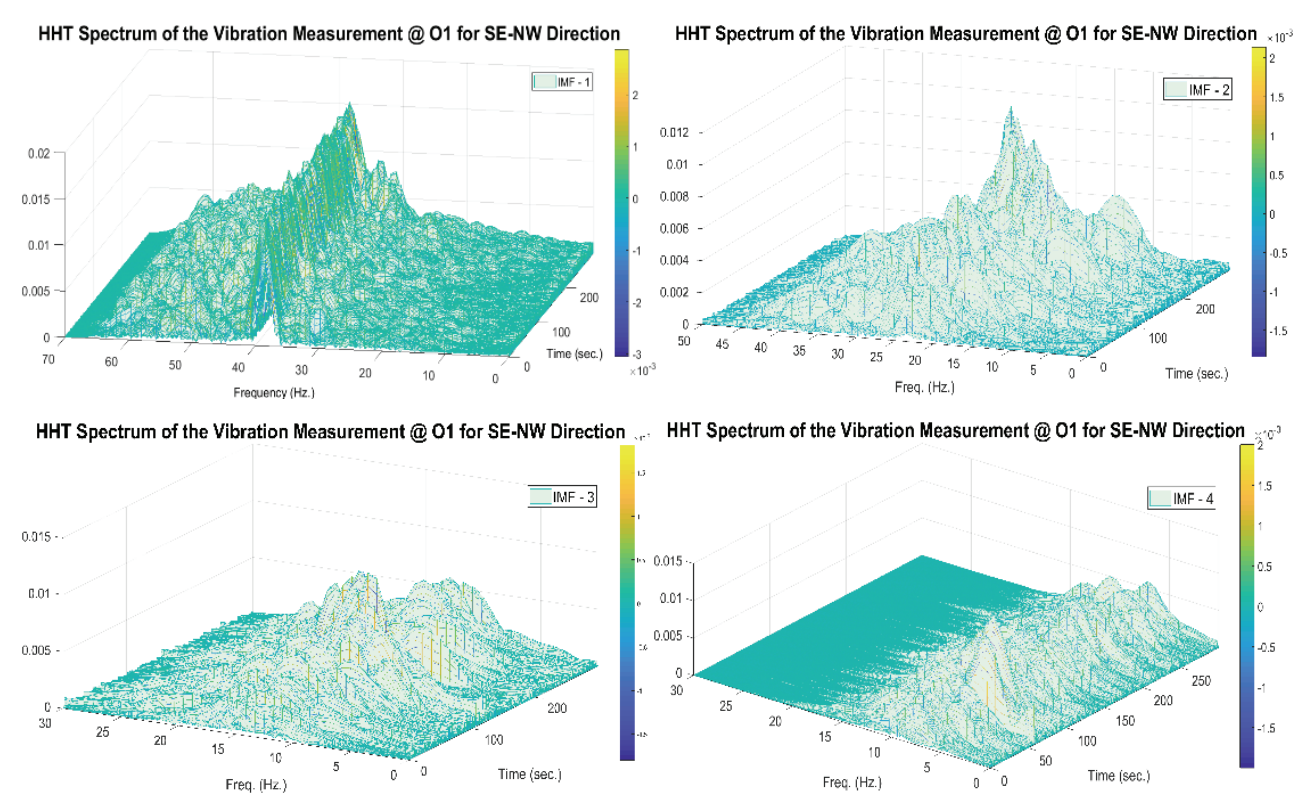

HHT Spectrum of the Vibration Measurement @ 01 for SE-NW Direction

Fig. 20 - Hilbert Spectra of the first four IMFs decomposed from recording at the station $O_{1}$.

Contribution of each frequency component in the instantaneous frequency vectors of the IMFs is summed for all the time locations. Depending on frequency resolution (i.e., unit frequency increment), values of the instantaneous frequencies are counted as the same frequency, if the frequencies are nearly close in one frequency step and amplitudes related to each frequency are summed as if they belong to the same frequency value. Adopting such approach, marginal Hilbert spectrum (MHS) is estimated for each IMF at the all observation stations. Summation will also produce smoothed MHS as seen in Fig. 22. Another important point in the instantaneous approach naturally coming from either decomposition technique or system dynamics is that some values are never reached in the instantaneous frequency vectors of the IMFs. Therefore, some frequency stations do not appear in the spectrum as having zero contribution in the global behavior. As a typical example, MHS of the arch stations $\mathrm{O}_{1}, \mathrm{O}_{2}, \mathrm{O}_{3}$ and $\mathrm{O}_{4}$ are given in Fig. 22. Contribution of each IMF and the analytical function for SE-NW direction can be easily distinguished when compared the amplitudes of the MHSs. From MHS of $O_{3}$, decomposed signal IMF-1 has the highest oscillatory characteristic with a broadband frequencies (i.e., over the frequency region between $10 \mathrm{~Hz}$ and $40 \mathrm{~Hz}$ ) but centered at about $19 \mathrm{~Hz}-21 \mathrm{~Hz}$ while IMF-2 has the peak at $24 \mathrm{~Hz}$ as the highest frequency signal with an amplitude, which is three times greater than IMF-1's. IMF-1 can be identified as the global characteristic and IMF-2 with extraordinary sharp peak and narrow band frequency characteristic may be produced by the local failure at the station-3 $\left(\mathrm{O}_{3}\right)$. MHS of the analytical function also shows same peak at $24 \mathrm{~Hz}$. Other small frequency peaks certainly belong to the global behaviors. 


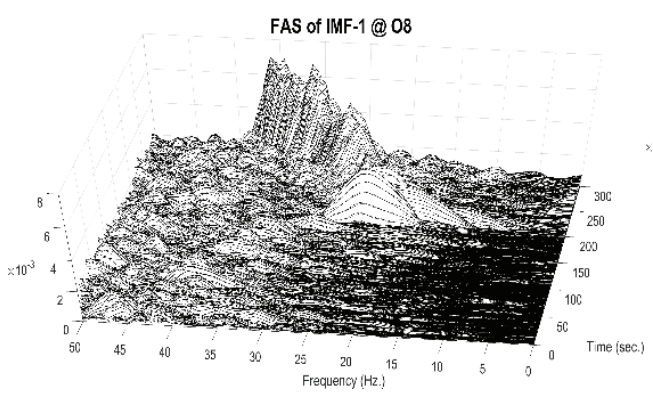

FAS of IMF-3 @ 08

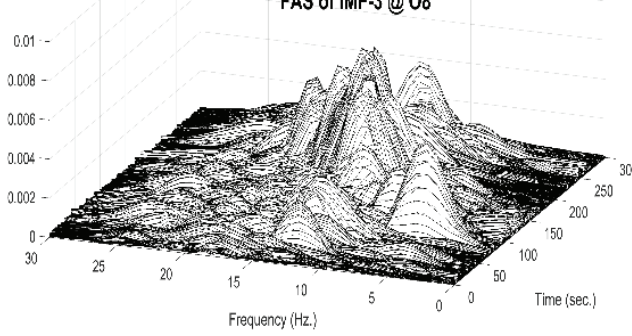

FAS of IMF-2 @08

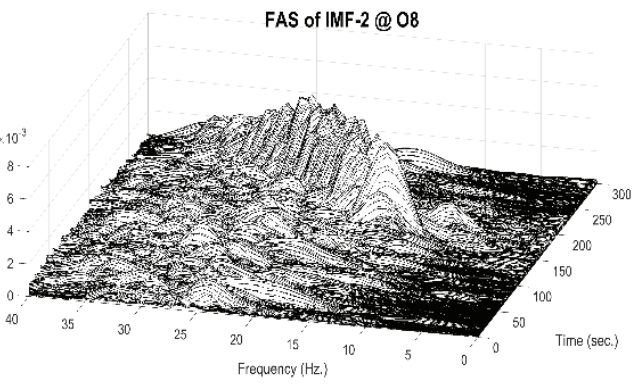

FAS of IMF-4@ 08

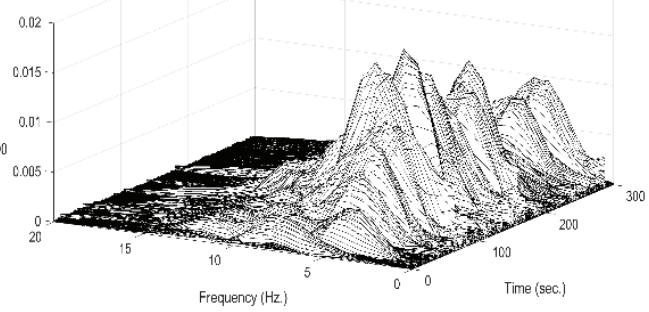

Fig. 21 - FAS of the first four IMFs decomposed from recording at the station $O_{8}$.
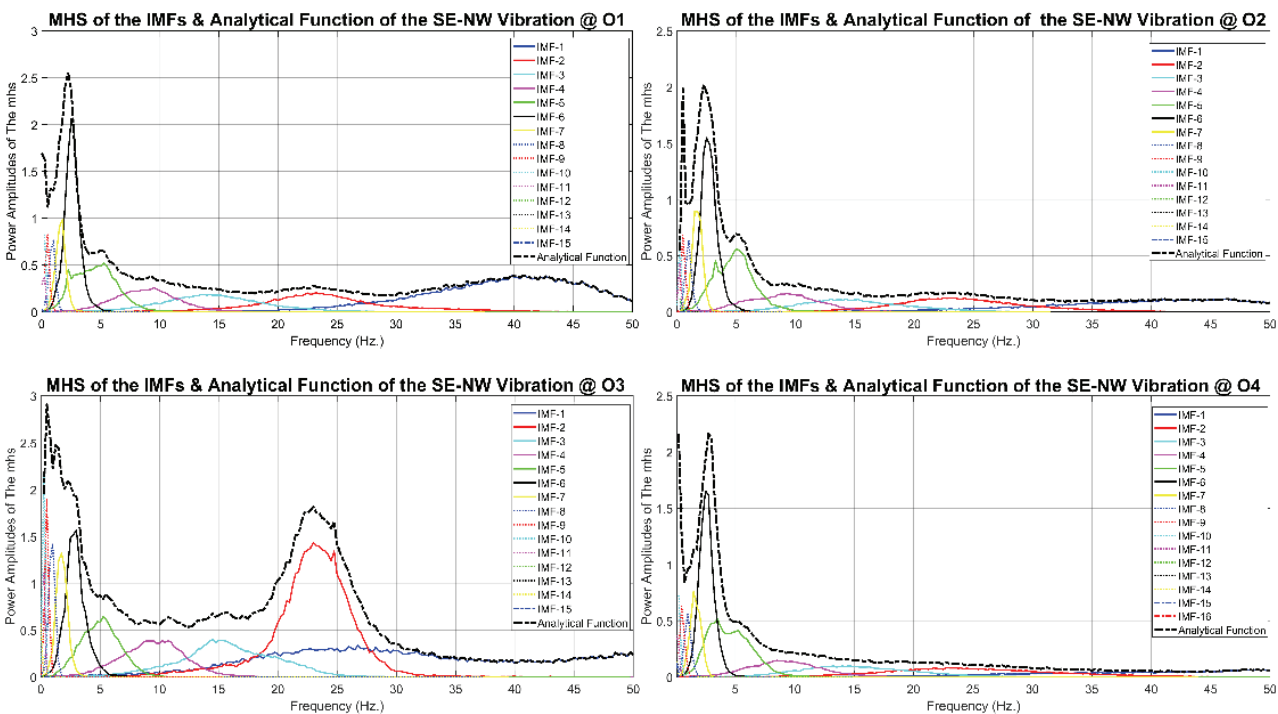

Fig. 22 - MHS of the IMFs decomposed from SE-NW ambient vibrations of the arch stations $\mathrm{O}_{1}, \mathrm{O}_{2}, \mathrm{O}_{3}$ and $\mathrm{O}_{4}$ and $\mathrm{MHS}$ of the analytical functions in dot-dash black line. 


\section{CONCLUSIONS}

This paper, as a state of the art and practice in the damage detection, presents a brief review of different damage identification methods and their applications to a historical structure, Fatih Mosque, damaged during the 1999 Kocaeli Earthquake. Spectral analysis of the structure yields average peak frequencies, respectively at around 2.5, 3.5, 4.3, 5.3 Hz for SENW direction. Similarly, for the SW-NE direction, they are at around 2.6, 3.2, 4.5-5.0 Hz with a broadband characteristic. From spectral and parametric results, Northwest arch $\left(\mathrm{O}_{3}\right)$ that is expected to move in harmony with other structural components will not display such a consistent behavior and produces additional local frequency at $24 \mathrm{~Hz}$ due to loose bonds between the stone masonry blocks around the crown. Southeast arch $\left(O_{l}\right)$ also has roughly comparable damage producing another locality at $38 \mathrm{~Hz}$. On a global scale, damage additionally generates significant source of the non-stationarity on the neighbors in touch. Northeast arch $\left(\mathrm{O}_{2}\right)$ is affected strongly by the anomalies appeared at stations $O_{3}$ and $O_{1}$. Especially the neighbor stations $O_{6}$ and $O_{7}$ located at the springing points of the $\operatorname{arch}\left(O_{3}\right)$ and others $O_{5}$ and $O_{6}$ located at the springing points of the arch $\left(O_{2}\right)$ are strongly affected due to tension rod failure causing the dome base to open outwards. Nonlinear behavior and strong nonstationary characteristics under the effect of accumulated damages are observed all neighbor components. It is seen that the progressive damage and partial failure destabilized the adjacent members. Analyses were extended to T-F decomposition in order (1) to describe how the spectral content of the signal changes with time; (2) to verify the effectiveness of the $\mathrm{T}-\mathrm{F}$ analysis in damage identification in case of ambient vibration recordings and (3) to discuss comparably well sides and significant doubts on the suitability of the techniques in damage identification studies. STFT, WT and HHT utilized as different vehicles were discussed to reexamine superior performance of the suitable one with some advantageous. Finally, useful quantitative information that was extracted from WT and HHT has achieved very close results about the damage and time varying spectral characteristics. On the other hand, since structural damages do not allow the structure to behave in a monotonic fashion, results of the different analysis methods in either way yield similar results but negligibly small differences in frequency content. In order to compensate the FT leakage artifacts (i.e., non-stationarity, zero end conditions), it is recommended to decompose the signal based on Huang before applying Fourier Transform for particularly nonstationary dynamics. Simulations show that the proposed algorithm has better performance in component extraction from complex nature as well as provides more time-frequency details than conventional Fourier Transform method. For historical masonry structures with vulnerable components like large central dome and arches that have low redundancy, there is a need to develop automatic signal/image processing to identify anomaly through image processing, machine vision, and pattern recognition. Ambient measurement data has enough sensitivity for advanced damage identification and adequately captures nonlinear nonstationary characteristics, if exist in the structural behavior.

\section{Acknowledgements}

To Prof. Dr. Feridun Çılı (İTÜ) for sharing his own photograph archive and co-author Haluk Y1ld1z (VGM) for providing the technical details and drawings. To the Y1lmaz Construction and Restoration Com. Yusuf Yılmaz and architect Mrs. Gülşah Altun for their help and availability. 


\section{References}

[1] Goodwin, Godfrey (1971), Gaspare Fossati Di Morcote and His Brother Giuseppe, A history of Ottoman Architecture, London.

[2] Hrvoje Smoljanović, Nikolina Živaljić, Željana Nikolić, Overview of the methods for the modelling of historical masonry structures, GRAĐEVINAR 65 (2013) 7, 603-618.

[3] Lourenço, P.B. 1998. Experimental and numerical issues in the modelling of the mechanical behavior of masonry. In: P. Roca et al. (Ed) Structural Analysis of Historical Constructions, p. 57-91, Barcelona: CIMNE.

[4] Allemang, R.J. 1984: Experimental Modal Analysis Bibliography. Proceedings of the $2^{\text {nd }}$ International Modal Analysis Conference, Orlando, Florida, 1085-1097.

[5] Doebling, S. W., Farrar, C. R., Prime, M B. and D W. Shevitz (1996), Damage identification and health monitoring of structural and mechanical systems from changes in their vibration characteristics: a literature review, Los Alamos National Loboratory report LA-13070-MS.

[6] Aktan, A. E., Hunt, V. J., Lally, M. J., Stillmaker, R. B.,Brown, D. L., and Shelley, S.J., (1995), "Field Laboratory for Modal Analysis and Condition Assessment of Highway Bridges', Proceedings of International Modal Analysis Conference XV, Honolulu, Hi., Pages 718-727.

[7] Straser, E.G. and Kiremijdian, A.S. (1996), A Modular Visual Approach to Damage Monitoring for Civil Structures. Proceedings of SPIE Smart Structures and Materials, $2719,112-122$.

[8] P.B. Lourenço, Computations on historic masonry structures, Prog. Struct. Eng. Mater. 4 (2002) 301-319.

[9] E. Quagliarini, G. Maracchini, F. Clementi, Uses and limits of the equivalent frame model on existing unreinforced masonry buildings for assessing their seismic risk: a review, J. Build. Eng. 10 (2017) 166-182.

[10] Daniele Pellegrini, Maria Girardi, Paulo B. Lourenço, Maria Giovanna Masciotta, Nuno Mendes, Cristina Padovani, Luis F. Ramos, Modal analysis of historical masonry structures: Linear perturbation and software benchmarking, Construction and Building Materials 189 (2018) 1232-1250

[11] A. Cabboi, C. Gentile, A. Saisi, From continuous vibration monitoring to FEM-based damage assessment: application on a stone-masonry tower, Constr. Build. Mater. 156 (2017) 252-265.

[12] B. Conde, L.F. Ramos, D.V. Oliveira, B. Riveiro, M. Solla, Structural assessment of masonry arch bridges by combination of non-destructive testing techniques and threedimensional numerical modelling: application to Vilanova bridge, Eng. Struct. 148 (2017) 621-638.

[13] L.F. Ramos, L. Marques, P.B. Lourenço, G. De Roeck, A. Campos-Costa, J. Roque, Monitoring historical masonry structures with operational modal analysis: two case studies, Mech. Syst. Signal Process. 24 (2010) 1291-1305. 
[14] P. Pineda, Collapse and upgrading mechanisms associated to the structural materials of a deteriorated masonry tower. Nonlinear assessment under different damage and loading levels, Eng. Fail. Anal. 63 (2016) 72-93. Elsevier.

[15] Alemdar Bayraktar, Ahmet Can Altunisik, Baris Sevim, Temel Türker, Seismic response of a historical masonry minaret using a finite element model updated with operational modal testing, J. Vib. Control 17 (1) (2011) 129-149.

[16] Dascotte, E. (2007), "Modal Updating for Structural Dynamics; Past, Present and Future Outlook", Int. Conf. on Engee. Dynamics (ICED), Algarve, Portugal.

[17] E. Bassoli, L. Vincenzi, A.M. D’Altri, S. De Miranda, M. Forghieri, G. Castellazzi, Ambient vibration-based finite element model updating of an earthquake-damaged masonry tower, Struct. Control Health Monit. 25 (5) (2018) e2150.

[18] M. Mistler, C. Butenweg, K. Meskouris, Modelling methods of historic masonry buildings under seismic excitation, J. Seismol. 10 (2006) 497-510.

[19] W. Torres, J.L. Almazán, C. Sandoval, R. Boroschek, Operational modal analysis and FE model updating of the Metropolitan Cathedral of Santiago, Chile, Eng. Struct. 143 (2017) 169-188.

[20] M.G. Masciotta, L.F. Ramos, P.B. Lourenço, The importance of structural monitoring as a diagnosis and control tool in the restoration process of heritage structures: a case study in Portugal, J. Cultral Heritage 27 (2017) 36-47.

[21] M.G. Masciotta, L.F. Ramos, P.B. Lourenço, M. Vasta, Damage identification and seismic vulnerability assessment of a historic masonry chimney, Ann. Geophys. 60 (4) (2017) 2017, https://doi.org/10.4401/ag-7126.

[22] B. Pantò, F. Cannizzaro, I. Caliò, P.B. Lourenço, Numerical and experimental validation of a 3D macro-model for the in-plane and out-of-plane behavior of unreinforced masonry walls, Int. J. Archit. Heritage 11 (7) (2017) 946-964.

[23] Ewins, D. J. (2000), Adjustment or Updating of Models, International Winter School on Optimum Dynamic Design Using Modal Testing and Structural Dynamic Modification, Indian Academy Sciences, 235-245.

[24] Beyen, K., 2005, 'Fatih Camii Yapısal Davranışının Ve Dinamik Özelliklerinin Çevrel Ölçümler Işı̆̆ında Tanımlanması', T.C. İstanbul Büyük Şehir Belediyesi İski Genel Müd., Mimtaş ile T.C. Boğaziçi Ü., T.C. Yıldız Teknik Ü. arasında İstanbul Fatih Camii ve Külliyesi Alt ve Üst Yapı Onarım - Restorasyon Projesi, İstanbul (in Turkish).

[25] Ceylan, Oğuz, Ocakcan, Tuğba Keleş, Fatih Camii 2007-2012 Restorasyonu Uygulamalar1 - The Restoration of Fatih Mosque Between 2007-2012, Vakıf Restorasyon Yıllığı, Yıl: 2013, Sayı: 7, (in Turkish).

[26] Beyen, K. (2008), "Structural Identification for Post-Earthquake Safety Analysis of the Fatih Mosque after the 17 August 1999 Kocaeli Earthquake", Engineering Structures, 30. 
[27] Farrar, C. R., Doebling S. W., Cornwell, P. J., and E. G. Straser (1997), "Variability of modal parameters measured on the Alamosa Canyon Bridge", in Proc., 15th Int. Modal Analysis Conf., Orlando, FL.

[28] Goodwin, Godfrey (1997), A History of Ottoman Architecture, Thames and Hudson, London, 121-131.

[29] Ayverdi, Ekrem Hakki (1973), Fatih Era in Ottoman Architecture - Osmanli Mimarisinde Fatih Devri: (1451-1481), Volume III, Baha Matbaasi, Istanbul, 356-387 (Turkish).

[30] Sakin, Orhan (2002), “Tarihsel kaynaklarıyla İstanbul Depremleri”, İstanbul, referenced Gregoras Nikephoros Historia, 2, p. 694.

[31] William S. Ginell and E. Leroy Tolles (2000), "Seismic Stabilization of Historic Adobe Structures", JAIC, Vol. 39, No: 1, 147-163.

[32] Bariola, J. B. (1991), "Dynamic stability of adobe walls", Ph.D. dissertation, University of Illinois, Urbana, Ill.

[33] Çılı, F. and Yıldız, H., 2013, 'Fatih Camii ve I. Mahmut Kütüphanesi Güçlendirme Çalışmaları - Strengthening Works of The Fatih Mosque and Mahmut I. Library', Vakıf Restorasyon Yillığ1, No: 7, pgs: $66-84$.

[34] Yılmaz Yapı Taah. Ve Tic. Ltd. Şti. Özel Fatih Camii Restorasyon Arşivi, 2019.

[35] Fatih Sultan Mehmet Camii ve Sultan I. Mahmut Kütüphanesi Restorasyonu (20082012), 2019, Yılmaz Yapı Taah. Ve Tic. Ltd. Şti. Yayınları, (baskıya hazırlanıyor in press).

[36] Durukal, E., Cimilli, S. and Erdik, M. (2003), "Dynamic Response of Two Historical Monuments in Istanbul Deduced from the Recordings of Kocaeli and Düzce Earthquakes", BSSA, Vol. 93, no. 2, 694-712.

[37] Rahmatalla, S., Eun, Hee-Chang, Lee, Eun_Taik (2012), "Damage detection from the variation of parameter matrices estimated by incomplete FRF data", Smart Structures and Systems, Vol. 9, No. 1, 55-70.

[38] Lus, H., De Angelis M, Betti, R., and Longman, R.W. (2003), “Obtaining Physical Parameters of Mechanical Systems from Identified State Space Models", ASCE, Journal of Engineering Mechanics, V. 129 (5), 477-488.

[39] Inman, D. J. and Minas, C. (1986), "Matching analytical models with experimental modal data in mechanical systems", Control and Dynamics Systems, Vol. 37, 327-363.

[40] Liu, S. C. and Yao, J. T. P. (1978), "Structural Identification Concept", ASCE Journal of the Structural Division, Vol. 104, No. ST12, 1845-1858.

[41] Law, S. and Li, X. (1993), "Structural damage detection based on higher order analysis", Procedings of Asia Pacific Vibration Conference, 640/3, Japan.

[42] Lim, T. W. (1990), "Submatrix approach to stiffness matrix correction using modal test data", AIAA Journal, Vol. 28, No.6, 1123-1130. 
[43] Bendat, J. S. and Piersol, A. G. (2004), Random Data, Analysis and Measurement Procedures, JW, USA.

[44] Juang, J. N. (1994), “Applied System Identification”, Prentice Hall, Englewood Cliffs, New Jersey.

[45] Juang, J. N., Pappa, R. S. (1985), “An Eigen system Realization Algorithm for Modal Parameter Identification and Model Reduction”, J. of Guidance, Control and Dynamics, 8, No.5.

[46] Bendat, J. S. (1990), Nonlinear System Analysis and Identification from Random Data, Wiley-Interscience, USA.

[47] Mathworks (2013), Signal Processing Toolbox for Matlab, Release 2012b, The MathWorks Inc., Natick, MA.

[48] Huang, N. E., Zheng, S., Long, S. R., Wu, M. C., Shih, H. H., Zheng, Q., Yen, N.-C., Tung, C. C., and Liu, H. H. (1998), "The empirical mode decomposition and Hilbert spectrum for nonlinear And nonstationary time series analysis.' Proc. R. Soc. London, Ser. A, 454. 